\title{
Comparison of model electron densities and temperatures with Millstone Hill observations during undisturbed periods and the geomagnetic storms of 16-23 March and 6-12 April 1990
}

\author{
A. V. Pavlov ${ }^{1,2}$ M. J. Buonsanto ${ }^{2}$ \\ ${ }^{1}$ Institute of Terrestrial Magnetism, Ionosphere and Radio-Wave Propagation, Russia Academy of Science (IZMIRAN), Troitsk, \\ Moscow Region, 142092, Russia \\ ${ }^{2}$ Haystack Observatory, Massachusetts Institute of Technology, Westford, Mass., USA
}

Received: 9 October 1995 / Revised: 31 July 1996 / Accepted: 6 August 1996

\begin{abstract}
Measurements of F-region electron density and temperature at Millstone Hill are compared with results from the IZMIRAN time-dependent mathematical model of the Earth's ionosphere and plasmasphere during the periods 16-23 March and 6-12 April 1990. Each of these two periods included geomagnetically quiet intervals followed by major storms. Satisfactory agreement between the model and the data is obtained during the quiet intervals, provided that the recombination rate of $\mathrm{O}^{+}\left({ }^{4} \mathrm{~S}\right)$ ions was decreased by a factor of 1.5 at all altitudes during the nighttime periods 17-18 March, 19-20 March, 6-8 April and 8-9 April in order to increase the NmF2 at night better to match observations. Good model/data agreement is also obtained during the storm periods when vibrationally excited $\mathrm{N}_{2}$ brings about factor-of-2-4 reductions in daytime NmF2. Model calculations are carried out using different expressions for the $\mathrm{O}^{+}-\mathrm{O}$ collision frequency for momentum transfer, and the best agreement between the electron-density measurements and the model results is obtained when the CEDAR interim standard formula for the $\mathrm{O}^{+}-\mathrm{O}$ collision frequency is used. Deviations from the Boltzmann distribution for the first five vibrational levels of $\mathrm{N}_{2}$ were calculated. The calculated distribution is highly non-Boltzmann at vibrational levels $j>2$, and the Boltzmann distribution assumption results in the increase of $10-30 \%$ in calculated NmF2 during the storm-time periods. During the March storm at solar maximum the model results obtained using the EUVAC solar flux model agree a little better with the observations in comparison with the EUV94 solar flux model. For the April storm period of moderate solar activity the EUV94X model results agree better with the observations in comparison to the EUVAC model.
\end{abstract}

\section{Introduction}

There are many physical models of electron density, $N_{e}$, in the $\mathrm{F}$ region of the ionosphere. These models solve the ion and electron continuity, momentum, and energy equations and have the capability to predict day-to-day variability of the ionosphere. The large uncertainties in the calculated neutral winds lead to errors in the plasma drift and, as a result, to errors in the calculated peak height of the F2 layer (hmF2). This problem was largely overcome when Buonsanto (1986), Miller et al. (1986), and Richards (1991) develped a technique for deriving equivalent neutral winds from the observed hmF2. This method with some modification is used in our model to carry out a comprehensive study of the response of the ionosphere to the March and April 1990 geomagnetic storms. These modeled results are compared with the data (Buonsanto et al., 1992a) and with ionospheric densities and temperatures calculated using the measured neutral winds and electric fields given by Buonsanto et al. (1992a) as input parameters for our theoretical model. However, we often do not have the observed $\mathrm{hmF} 2$, and the problem of uncertainties in the calculated neutral winds arises again. In this case we can use the IRI hmF2, (Bilitza, 1990) to avoid some errors in the electron density during magnetic storms (Pavlov, 1996). In this paper, we use this new approach for the March and April 1990 geomagnetic storms (Buonsanto et al., 1992a) to estimate the inaccuracies in the prediction of the modeled $\mathrm{NmF} 2$ and $\mathrm{hmF} 2$. We compare our results and conclusions with modeling results given by Richards et al. (1994b) for the March 1990 magnetic storm.

The resonant charge transfer interaction between $\mathrm{O}^{+}$ and $\mathrm{O}$ is of great importance in ionospheric modeling (Moffett et al., 1990). Uncertainties in their crossections give inaccurate values for the momentum transfer collision frequency of $\mathrm{O}^{+}-\mathrm{O}$. The commonly accepted value of the $\mathrm{O}^{+}-\mathrm{O}$ frequency is given by Banks (1966) as 
$v_{\text {in }}(\mathrm{B})=3.5 \cdot 10^{-17} T^{0.5}(1-0.065 \log T)^{2}[\mathrm{O}]$,

where $T=\left(T_{i}+T_{n}\right) / 2$.

The most recent theoretical developments of this ionneutral collision frequency can be represented (Pesnell et al., 1993) by

$v_{\text {in }}(\mathrm{P})=5.9 \cdot 10^{-17} T^{0.5}(1-0.096 \log T)^{2}[\mathrm{O}]$.

From indirect measurements of this frequency it follows that the value of $v_{\text {in }}(B)$ must be increased by factor 1.2 2.4 (Burnside et al., 1987; Sipler et al., 1991., Buonsanto et al., 1992b; Reddy et al.,1994; Davis et al., 1995). The recommended interim standard for momentum transfer collision frequency of $\mathrm{O}^{+}-\mathrm{O}$ adopted at the 1992 CEDAR meeting is given by Salah (1993) as

$v_{\text {in }}(\mathrm{S})=4 \cdot 10^{-17} T^{0.5}[\mathrm{O}]$.

The difference between $v_{\text {in }}(\mathrm{P})$ and $v_{\text {in }}(\mathrm{S})$ is not only in the number coefficient but also in the temperature dependence of this frequency. In this paper, we examine which collision-frequency formula, that of Banks (1966), Pesnell et al. (1993), or Salah (1993) can produce the best agreement between observed and predicted values of $\mathrm{NmF} 2$ and $\mathrm{hmF} 2$ at Millstone Hill.

The March and April 1990 geomagnetic storms were at solar maximum and moderate solar-activity conditions when the vibrationally excited nitrogen played an important role in the ionosphere (Torr and Torr, 1982; Pavlov, 1988; Richards and Torr, 1986; Pavlov, 1994). That is why it is important to investigate the role of the vibrationally excited nitrogen in producing the negative phases of these ionospheric storms.

In earlier studies, Newton et al. (1974) and Pavlov (1989) found that deviation from a Boltzmann distribution of $\mathrm{N}_{2}(v)$ was large in the SAR-arc region at the vibrational energy levels $v>2$, and this deviation significantly affected the loss rate, $L$, of the $\mathrm{O}^{+}\left({ }^{4} \mathrm{~S}\right)$ ions at F2-region altitudes. Torr and Torr (1982) calculated a vibrational distribution of $\mathrm{N}_{2}(v)$ during undisturbed conditions at middle latitudes. Richards et al. (1986) studied the effects of the vibrationally excited nitrogen on the electron temperature, $T_{e}$, during quiet periods for a non-Boltzmann distribution of $\mathrm{N}_{2}(v)$. Pavlov and Namgaladze (1988) calculated a vibrational distribution of $\mathrm{N}_{2}(v)$ and found that the difference between the Boltzmann and non-Boltzmann distribution of $\mathrm{N}_{2}(v)$ does not have any effect on the electron density and temperature at solar minimum. Previous work concerning the role played by vibrationally excited molecular nitrogen in the formation of the disturbed F-region electron density and temperature have assumed a Boltzmann distribution of $\mathrm{N}_{2}(v)$. In this paper we will examine the effect of a non-Boltzmann distribution of $\mathrm{N}_{2}(v)$ on the electron density and temperature during geomagnetic storms.

Large, short-lived electric fields are often observed in the mid-latitude trough (Rodger et al., 1992). The perpendicular electric fields $\mathrm{E}_{\perp}$ (with respect to the magnetic field) produce significant effects in $N_{e}$ and the ion temperature, $T_{i}$ (Schunk et al., 1975; Raitt et al., 1976). These changes in the electron density and ion temperature are the reason for the electron-temperature disturbances. These electric fields were stronger during the April 1990 storm than during the March 1990 storm at Millstone Hill (Buonsanto et al., 1992a). During the day on 10 April 1990, extremely low values of $\mathrm{hmF} 2<200 \mathrm{~km}$ (indicating an F1 peak due to molecular ions) and high ion velocities in excess of 500 $\mathrm{ms}^{-1}$ were observed above Millstone Hill (Buonsanto et al., 1992a). These could be due to the perpendicular electric fields. An important aim of this paper is to study the effects of these $E_{\perp}$ on $N_{e}$. Our task is also to estimate the values of these electric fields needed to produce agreement between the measured and calculated $\mathrm{hmF} 2$ and the measured and calculated ion temperatures during the day on 10, April 1990 and to compare these electric fields with the measured electric fields given by Buonsanto et al. (1992a).

By using a theoretical model we can forecast the values of $\mathrm{NmF} 2$ and $\mathrm{hmF} 2$ during magnetic storms. Such predictions of $\mathrm{NmF} 2$ and $\mathrm{hmF} 2$ are also possible to carry out using the semiempirical IRI approach described by Kishcha (1995). During geomagnetic storms and substorms this analytical approach gives deviations of $\mathrm{NmF} 2$ and $\mathrm{hmF} 2$ from quiet condition values of $\mathrm{NmF} 2$ and $\mathrm{hmF}$. We also compare the accuracy of the theoretical and semiempirical IRI approach.

\section{IZMIRAN model}

The model of the thermal plasma in the ionosphere and plasmasphere used in the present study is described in detail by Pavlov (1994), and hence only a brief description will be given here. The IZMIRAN model is a one-dimensional model that uses a titled dipole approximation to the Earth's magnetic field and takes into account the difference between geographic and magnetic axes. In the model, coupled time-dependent equations of continuity, momentum, and energy balance for $\mathrm{O}^{+}\left({ }^{4} \mathrm{~S}\right)$ and $\mathrm{H}^{+}$ions and electrons, are solved along a centered-dipole magnetic field line for the concentrations, field-aligned diffusion velocities, and temperatures of ions and electrons from a base altitude $(160 \mathrm{~km}$ in the present study) in the northern hemisphere through the plasmasphere to the same base altitude in the southern hemisphere. Electron heating due to photoelectrons is provided by a solution of the Boltzmann equation for photoelectron flux along the entire flux tube using the method of Krinberg and Tashchilin (1984) on the same field-line grid used in solving the densities and temperatures. In the northern and southern hemispheres the IZMIRAN model solves time-dependent continuity equations for $\mathrm{O}^{+}\left({ }^{2} \mathrm{D}\right), \mathrm{O}^{+}\left({ }^{2} \mathrm{P}\right), \mathrm{O}\left({ }^{1} \mathrm{D}\right)$ vibrationally excited nitrogen quanta, and the momentum equations for the horizontal components of thermospheric wind within the altitude range $120-700 \mathrm{~km}$ and timedependent continuity equations for $\mathrm{NO}^{+}, \mathrm{O}_{2}^{+}$, and $\mathrm{N}_{2}^{+}$ 
ions in the region between 120 and $500 \mathrm{~km}$ in altitude. In order to take into account the strong dependence of the $\mathrm{O}^{+}\left({ }^{4} \mathrm{~S}\right)+\mathrm{N}_{2} \rightarrow \mathrm{NO}^{+}+\mathrm{N}$ reaction rate on vibrational excitation of $\mathrm{N}_{2}$ (Schmeltekopf et al., 1968; Van Zandt and O' Malley, 1973; Pavlov, 1988) the number densities of excited molecular nitrogen at the first five vibrational levels are determined from the Boltzmann distribution using the calculated vibrationally excited nitrogen quanta. In the photochemical scheme described by Pavlov (1994) we changed the rate coefficients of the reactions of $\mathrm{O}^{+}\left({ }^{2} \mathrm{P}\right)$ with $\mathrm{N}_{2}$ and $\mathrm{O}$ as recommended by Chang et al. (1993). To calculate more exactly the electron temperature from the electron-energy equation, we used the approximation to the multicomponent electron thermal conductivity coefficient given by Pavlov (1996). The model includes the option to use the models of the $\mathrm{O}^{+}-\mathrm{O}$ collision frequency given by Banks (1966), Pesnell (1993), and Salah (1993).

The distribution of ionization in the topside ionosphere and plasmasphere is strongly controlled by the geomagnetic field, and therefore the IZMIRAN model calculations are valid up to $L \approx 6$ ( $L$ is the shell value of the geomagnetic field) where the geomagnetic field is close to the dipole approximation (Krinberg and Tashchilin, 1984). The model cannot give a correct description of the ionosphere between $-20^{\circ}$ and $20^{\circ}$ magnetic latitude, which would require taking into account the exchange by ions and electrons between all magnetic tubes because of the action of electromagnetic drift.

The three key inputs to the IZMIRAN model are the concentrations and temperature of the neutral constituents, the solar EUV fluxes, and the plasma drift velocity. To simulate the magnetic-storm effects on the neutral atmosphere, the MSIS-86 model (Hedin, 1987) was run using the 3-h $A_{p}$ indices, while the solar EUV fluxes are from the EUVAC model (Richards et al., 1994a) or EUV94X model (Tobiska, 1993, 1994). To maintain the model nighttime $\mathrm{E}$ and $\mathrm{Fl}$ regions of the ionosphere, the simple approach to describe the neutral ionization by scattered solar 121.6-, 102.6-, and 58.4-nm radiation fluxes is used (Kashirin, 1986). The large uncertainties in the plasma drift velocity lead to errors in the calculated peak height of the F2 layer. Therefore, in the northern hemisphere, instead of calculating thermospheric wind components by solving the momentum equations given by Pavlov (1994), we use the approach developed by Richards (1991) to calculate an equivalent neutral wind from the hmF2 measurements given by Buonsanto et al. (1992a). Our implementation of the Richards (1991) method is explained in Appendix A. For the March and April 1990 magnetic storms we also use the measured neutral winds and electric fields given-by Buonsanto et al. (1992a) as input parameters for our theoretical model. The major enhancement to the IZMIRAN model described by Pavlov (1994) is the inclusion of electric-field effects on $N_{e}$ and $T_{i}$ in the frame of the onedimensional IZMIRAN model as described by Pavlov (1996). Finally, the new approach given by Pavlov (1996) is applied to estimate the errors in NmF2 and hmF2 for the geomagnetic storms when the observed hmF2 are unavailable.

\section{Undisturbed period and storms of 16-23 March 1990}

The undisturbed period of 16-17 March $1990\left(A_{p}\right.$ of 8 and 3) and the 18-23 March 1990 magnetic storms $\left(A_{p}\right.$ between 14 and 73) occurred at solar maximum where the $10.7-\mathrm{cm}$ solar flux increased from 180 on 16 March to 247 on 23 March. During 18-23 March 1990 two geomagnetic storms took place: a minor storm with a gradual commencement time near 0400 UT on 18 March and a major storm with a sudden commencement time near 2245 UT on 20 March. The data used in this paper (the variations of electron density and temperature) were taken by the incoherent-scatter radar at Millstone Hill, Massachusetts (Buonsanto et al., 1992a).

Figure 1 is a plot of the measured hmF2 and NmF2 for the period 16-23 March 1990 and the model results with and without effects of vibrationally excited $\mathrm{N}_{2}$ included in the calculated $\mathrm{O}^{+}\left({ }^{4} \mathrm{~S}\right)$ recombination rate
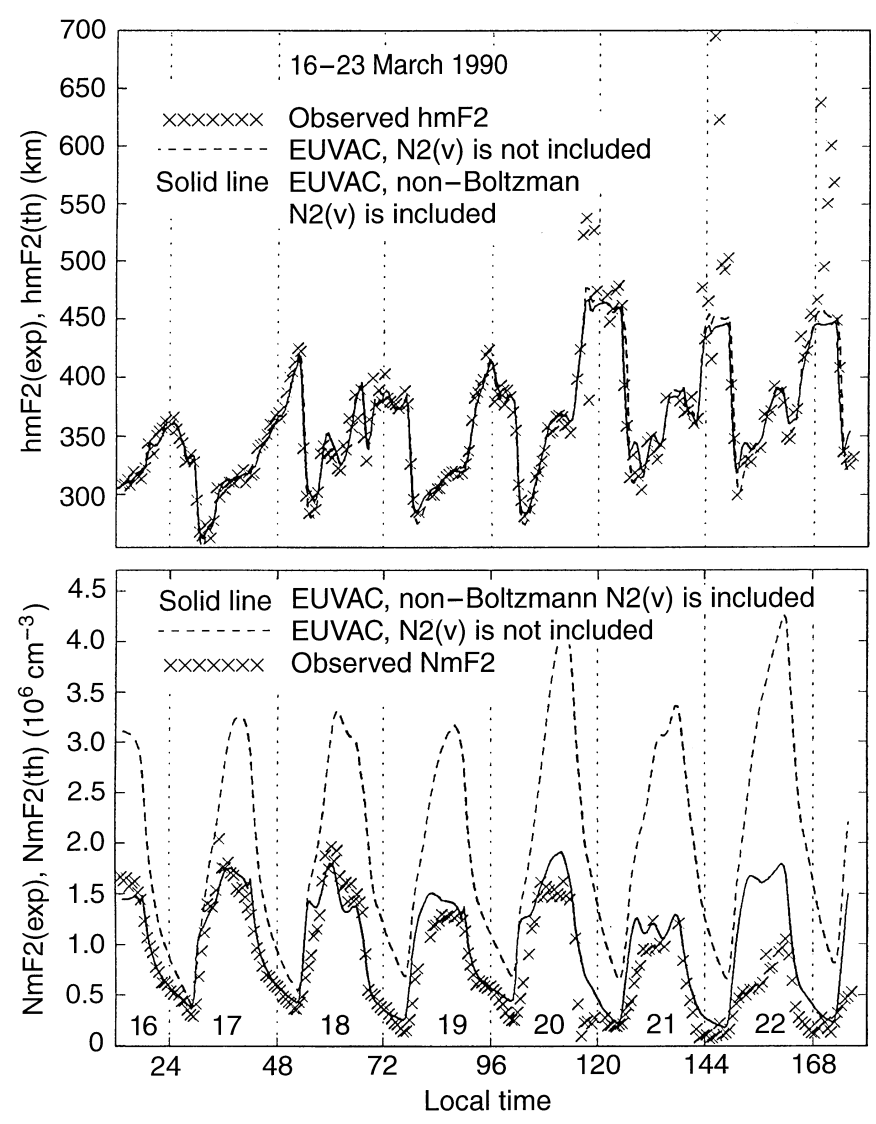

Fig. 1. Observed (crosses) and calculated $\mathrm{F} 2$ peak parameters above Millstone Hill for 16-23 March 1990. (Top) hmF2. (Bottom) NMF2. The solid lines are $\mathrm{hmF} 2$ and $\mathrm{NmF} 2$ from the IZMIRAN model when the non-Boltzmann populations of the first five vibrational levels of $\mathrm{N}_{2}(v)$ are included in the calculated $\mathrm{O}^{+}\left({ }^{4} \mathrm{~S}\right)$ recombination rate, and this recombination rate was decreased by the factor 1.5 during the nighttime periods of 16-18 and 19-20 March with solar zenith angles more than $90^{\circ}$, and dashed lines are hmF2 and $\mathrm{NmF} 2$ when $\mathrm{N}_{2}(v)$ is not included in the calculations with the original $\mathrm{O}^{+}\left({ }^{4} \mathrm{~S}\right)$ recomibination rate. The EUVAC solar flux model, the method of Eqs. A.18, A.20 for obtaining equivalent neutral winds from the height of the $\mathrm{F} 2$ peak electron density, and the $\mathrm{O}^{+}-\mathrm{O}$ collision frequency given by Salah (1993) were used in the IZMIRAN model 
which will be explained later. There are clear negative and positive phases in NmF2 compared to the undisturbed NmF2 on 17 March with the largest negative phase near 2030 LT on 20 March.

\subsection{Uncertainties in the collision frequency of $\mathrm{O}^{+}-\mathrm{O}$ and the loss rate of the $\mathrm{O}^{+}\left({ }^{4} \mathrm{~S}\right)$ ions}

The uncertainties associated with the $\mathrm{O}^{+}-\mathrm{O}$ collision crossection give the uncertainty in the $\mathrm{O}^{+}-\mathrm{O}$ collision frequency. In this paper, we use two theoretical approaches given by Eqs. 1 and 2 (Banks, 1966, and Pesnell, 1993, respectively) and Eq. 3, the CEDAR interim standard for the $\mathrm{O}^{+}-\mathrm{O}$ frequency (Salah, 1993). The $\mathrm{O}^{+}-\mathrm{O}$ frequency given by Pesnell (1993) is larger than that given by Banks (1966) and less than that given by Salah (1993). Solid and dashed lines of Fig. 2 give the comparison of the modeled densities using two different
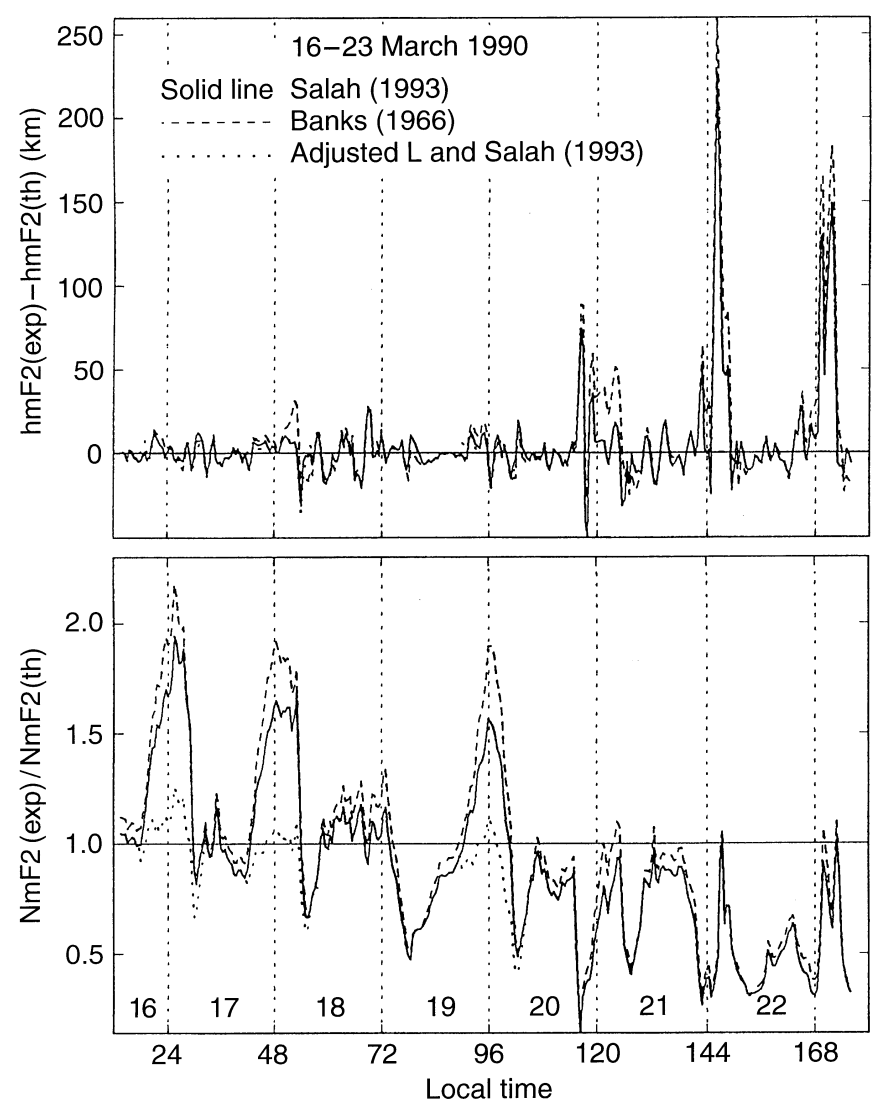

Fig. 2. (Top) Differences between the measured hmF2(exp) and the modeled $\mathrm{hmF}$ (th), and ratios of the measured $\mathrm{NmF}$ (exp) to the modeled NmF2(th) (bottom) for the magnetically quiet and disturbed periods of 16-23 March 1990 for the EUVAC solar flux model. The model results were obtained using the method of Eqs. A.18, A.20 for obtaining equivalent neutral winds from the height of the F2 peak electron density with the original $\mathrm{O}^{+}\left({ }^{4} \mathrm{~S}\right)$ recombination rate ( solid and dashed lines) and when this recombination rate was decreased by the factor 1.5 during the nighttime periods 16-18 and 19-20 March with solar zenith angles more than $90^{\circ}$ (dotted lines). The $\mathrm{O}^{+}-\mathrm{O}$ collision frequencies given by Salah (1993) (solid and dotted lines) and Banks (1966) (dashed lines) were used in the IZMIRAN model assumptions Eqs. 1 and 3. We can see that the $\mathrm{O}^{+}-\mathrm{O}$ frequency of Salah (1993) gives the best agreement between measured and modeled NmF2. The method based on the Richards (1991) approach (Eqs. A.18, A.20) will naturally mimic the measured $\mathrm{hmF} 2$ during the quiet and disturbed periods on 16-21 March. Significant errors in the calculated $\mathrm{hmF} 2$ during 22 and 23 March are the result of the rapid fluctuations in the measured $\mathrm{hmF} 2$. There is the excellent agreement between the modeled NmF2 and the data on days 1618. During 16-19 March the disagreement between measured and modeled $\mathrm{NmF} 2$ is not more than a factor of 2 .

The results of Fig. 2 show that the use of the frequency given by Banks (1966) leads to a $5-10 \%$ decrease in the calculated daytime $\mathrm{NmF} 2$ and up to about $25 \%$ at night in comparison with $\mathrm{NmF} 2$ calculated by using the frequency given by Salah (1993). In order to illustrate the basic physics involved and to find out the physical reasons of this nighttime difference (but not for calculations) it is useful to use the analytical description of the nighttime $\mathrm{NmF} 2$ given by Krinberg and Tashchilin $(1982,1984)$ :

$$
\begin{aligned}
\mathrm{NmF} 2(\mathrm{t}) \approx & \mathrm{NmF} 2\left(t_{0}\right) \exp \left[-\left(t-t_{0}\right) L(t)\right] \\
& +3 F_{\infty}(t) T_{n}(t) v_{i n}(t) /\left[T_{i}(t)+T_{e}(t)\right] / g,
\end{aligned}
$$

where

$L=\sum_{j=0}^{5} k_{j}\left[\mathrm{~N}_{2}(j)\right]+\gamma\left[\mathrm{O}_{2}\right]$,

$k_{j}$ and $\gamma$ are the recombination rate coefficients of $\mathrm{O}^{+}\left({ }^{4} \mathrm{~S}\right)$ ions with $\mathrm{N}_{2}(j=0-5)$ and $\mathrm{O}_{2}, \mathrm{NmF} 2\left(t_{0}\right)$ is the ionospheric electron density for the local time $t_{0}$ corresponding to dusk, $T_{n}$ is the exospheric neutral temperature, $T_{j}$ and $T_{e}$ are ion and electron temperatures, $g$ is the acceleration due to gravity, $v_{\text {in }}$ is the $\mathrm{O}^{+}-\mathrm{O}$ collision frequency, $F_{\infty}$ is the value of plasma ion flux flowing from the plasmasphere into the ionosphere, the values of $L, T_{i}, T_{e}, g$ and $v_{\text {in }}$ are chosen at the F2-peak altitude.

We can see from (4) that the nighttime F2-region electron density consists of two parts. The first term describes the role of the daytime ionization in the maintenance of the nighttime ionosphere. In this case the $\mathrm{F}$ region would decay with the characteristic time $\sim L^{-1}$ ( $\sim$ several hours). The nocturnal $\mathrm{F}$ region is also maintained by a downward flow of ionization from the plasmasphere described by the second term in Eq. 4. In winter, in spring, and in autumn, when the night is long enough, the role of the second term in Eq. 4 increases before sunrise and this term determines $\mathrm{NmF} 2$ as a function of $v_{\text {in }}$.

It seems likely that the nighttime discrepancy between measured and modeled $\mathrm{NmF} 2$ is caused by inaccuracies in key inputs, such as the composition and temperature of the neutral atmosphere (the MSIS-86 model does not accurately predict the neutral atmosphere during the quiet period and the magnetic storm), and the recombination rate coefficients of $\mathrm{O}^{+}\left({ }^{4} \mathrm{~S}\right)$ ions with $\mathrm{N}_{2}(j=0-5)$ and $\mathrm{O}_{2}$. 
Dotted lines on Fig. 2 show the model results when the recombination rate of the $\mathrm{O}^{+}\left({ }^{4} \mathrm{~S}\right)$ ions was decreased by a factor of 1.5 by decreasing the MSIS- $86 \mathrm{~N}_{2}$ and $\mathrm{O}_{2}$ densities by 1.5 at all altitudes during the nighttime 16 18 March and 19-20 periods when the solar zenith angle was more than $90^{\circ}$ in the northern hemisphere. No adjustments were made to the $L$ values at any other times. This recombination rate adjustment is sufficient in order to reproduce very well the observed nighttime NmF2 on 17-18 March and 19-20 March.

As Fig. 2 shows, there is large disagreement between the measured and modeled NmF2 on 22-23 March. The $\mathrm{F}$ region was depleted during this time period, as the main ionospheric trough moved equatorward of Millstone Hill (Buonsanto et al., 1992a). Enhanced sunward convection (500-1700 m s${ }^{-1}$ ) was observed on 22 March. These large ion drift velocities are the subauroral ion drift phenomenon (Foster et al., 1994), and therefore we can assume these drifts were connected with large, shortlived electric fields ( up to 1-3 h) often observed in the mid-latitude trough (Rodger et al., 1992). These electric fields can have important effects on $N_{e}$ and the ion temperature. The rate coefficients of such important ionospheric processes as the reactions of $\mathrm{O}^{+}\left({ }^{4} \mathrm{~S}\right)$ with $\mathrm{N}_{2}$ and $\mathrm{O}_{2}$ depend on the effective temperature, which is a function of the ion temperature, the neutral temperature, and the plasma drift velocity (Albritton et al., 1977; St.-Maurice and Torr, 1978). These effects are not taken into account in the model used here, giving the mentioned disagreement between the measured and calculated NmF2. Some results of these effects of electric fields on the electron density are presented in Sect. 5.

\subsection{Vibrationally excited nitrogen}

In the IZMIRAN model, the number densities, $n_{j}$, of excited molecular nitrogen $\mathrm{N}_{2}(j)$ at the vibrational level, $j$, are determined from the Boltzmann distribution

$$
n_{j \mathrm{~B}}=n_{0 \mathrm{~B}}[\alpha /(1+\alpha)]^{j}=n_{0 \mathrm{~B}} \exp \left(-j T_{v}\right) \text {, }
$$

where $\alpha$ is the vibrational quanta and $T_{v}$ is the vibrational temperature. In this case, from Eq. 6 follows that the sum of the vibrationally unexcited and excited molecular nitrogen concentrations (Pavlov and Namgaladze, 1988):

$\left[\mathrm{N}_{2}\right]=n_{0 \mathrm{~B}}(1+\alpha)$.

There is no possibility to differentiate the vibrationally unexcited $\mathrm{N}_{2}$ from the vibrationally excited $\mathrm{N}_{2}$ during the mass-spectrometer measurements of the neutral species in the atmosphere, and therefore we believe that the MSIS- 86 model calculates the value of $\left[\mathrm{N}_{2}\right]$. The difference between $\left[\mathrm{N}_{2}\right]$ and $n_{0 B}$ is not negligible for the March 1990 magnetic storm. For example $\left[\mathrm{N}_{2}\right] / n_{0 B}=$ 1.12 for $T_{v}=1500 \mathrm{~K}$.

The ability of the IZMIRAN model to reproduce the measured NmF2 is illustrated in Fig. 3. The solid line is a model result when the vibrationally excited nitrogen is included in the calculations of the loss rate $L$ of the $\mathrm{O}^{+}\left({ }^{4} \mathrm{~S}\right)$ ions as determined by Eq. 5 . The dashed lines in Figs. 1 and 3 are model results when the vibrationally excited nitrogen is not included in the calculations of $L$ with $k_{j}(j>0)=0$ and $L=k_{0}\left[\mathrm{~N}_{2}\right] /(1+\alpha)+\gamma\left[\mathrm{O}_{2}\right]$. The approach based on the Richards (1991) method (Eqs. A.18, A.20) for obtaining equivalent neutral winds from the height of the $\mathrm{F} 2$ peak electron density and the $\mathrm{O}^{+}-\mathrm{O}$ frequencies given by Salah (1993) were applied to the model. From Figs. 1 and 3 it follows that there is a large increase in the modeled NmF2 without the vibrationally excited nitrogen and the model densities are unreliable. Both the daytime and nighttime densities are not reproduced by the model without the vibrationally excited nitrogen. Inclusion of vibrationally excited $\mathrm{N}_{2}$ brings the model and data into agreement. The increase in the $\mathrm{O}^{+}+\mathrm{N}_{2}$ rate factor due to the vibrationally excited nitrogen produces factors of 2-4 reductions in the daytime peak density. The effect of vibrationally excited $\mathrm{N}_{2}$ on $N_{e}$ is most pronounced during the daytime.

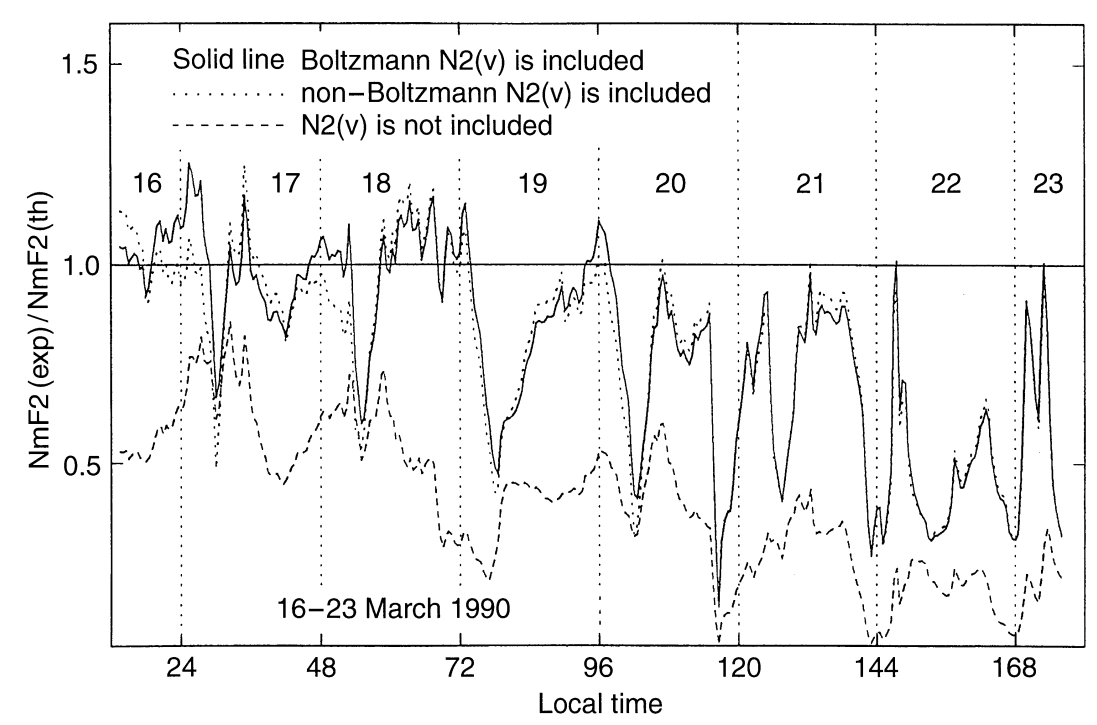

Fig. 3. Ratios of the measured F2 peak densities NmF2(exp) to the modeled F2 peak densities NmF2(th) during the 16-23 March 1990 period for the EUVAC solar flux model. The modeled $\mathrm{NmF} 2$ were obtained using the Boltzmann vibrational distribution of $\mathrm{N}_{2}(v)$ (solid line) and the nonBoltzmann populations of the first five vibrational levels by solving the $\mathrm{N}_{2}(v=1-5)$ time-dependent continuity equations (dotted line), and when $\mathrm{N}_{2}(v)$ was not included in the calculations (dashed line). The original $\mathrm{O}^{+}\left({ }^{4} \mathrm{~S}\right)$ recombination rate was decreased by the factor 1.5 during the nighttime periods 16-18 and 19-20 March and the $\mathrm{O}^{+}-\mathrm{O}$ collision frequencies given by Salah (1993) were used in the IZMIRAN model 


\subsection{Non-Boltzmann distribution of vibrationally excited molecular nitrogen}

There are some deviations of $n_{j}$ from $n_{j B}$ in the F region of the ionosphere (Newton et al., 1974; Torr and Torr, 1982; Richards et al., 1986; Pavlov, 1988, 1989, Pavlov and Namgaladze, 1988). These deviations can affect the recombination rate of $\mathrm{O}^{+}\left({ }^{4} \mathrm{~S}\right)$ ions and the heating rate of electrons due to the de-excitation reactions of excited molecular nitrogen. In order to study the possible effects of deviations of $n_{j}$ from $n_{j B}$ on the electron temperature and density let us consider the model description of excited molecular nitrogen.

Pavlov $(1988,1989)$ treated the vibrationally excited nitrogen molecule as a set of harmonic and anharmonic oscillator energy levels. The Pavlov (1989) study suggests that the effect of anharmonicity on $n_{j}$ is small at the energy levels, $j=1-5$. Therefore our model used the system of Eqs. 15-18 given by Pavlov (1988) to determine $n_{j}(j=1-5)$ using the harmonic oscillator energy level approximation, the vibrational-vibrational and vibrational-translational energy exchange of $\mathrm{N}_{2}(j)$, the diffusion of $\mathrm{N}_{2}(j)$ in the mixture of $\mathrm{N}_{2}(0), \mathrm{O}_{2}$, and $\mathrm{O}$, and the production rates of $\mathrm{N}_{2}(j)$ by thermal electron excitation of $\mathrm{N}_{2}(0)$, and by the reactions $\mathrm{O}\left({ }^{1} \mathrm{D}\right)$ with $\mathrm{N}_{2}(0)$ and $\mathrm{N}\left({ }^{4} \mathrm{~S}\right)$ with NO. This system of equations is numerically integrated within the altitude range $120-700 \mathrm{~km}$ in the northern and southern hemispheres. At the lower boundary the diffusion processes of vibrationally excited molecules were neglected. The upper-boundary conditions are zero fluxes for all excited levels. In order to calculate the value of $n_{5}$ it is required to know the value of $n_{6}$. By analogy with the Boltzmann distribution the condition $n_{6} / n_{5}=n_{5} / n_{4}$ was assumed.

The results of calculating $n_{j} / n_{j B}$, and $T_{n}$ are presented in Fig. 4. The present study suggests that the calculated distribution is highly non-Boltzmann at the vibrational levels $j>2$ just after sunrise. The deviations from the Boltzmann distribution are not significant at the first and second vibrational levels of $\mathrm{N}_{2}$. These relative deviations increase with level number and approach factors of 6 and 38 for the third and the fourth excited levels. The deviations $n_{3} / n_{3 \mathrm{~B}}$ and $n_{4} / n_{4 \mathrm{~B}}$ have their maximum values during the period 6.30-7.30 LT. From the diurnal variations of the calculated vibrational (solid line) and neutral (dashed line) temperatures shown in Fig. 4 it follows that $T_{v}<T_{n}$ is realized in the atmosphere for the nighttime periods where the produc-

Fig. 4. The time variations of the vibrational and neutral temperatures and populations of the first five vibrational levels of $\mathrm{N}_{2}$ in comparison with the Boltzmann distribution during the 16-23 March period at the F2 peak altitude. The solid lines show the modeled $T_{y}, n_{1} / n_{1 B}, n_{3} / n_{3 B}$, and $n_{5} / n_{5 B}$ and the dashed lines show the modeled $T_{n}, n_{2} / n_{2 B}$, and $n_{4} / n_{4 B}$. The $\mathrm{O}^{+}-\mathrm{O}$ frequencies given by Salah (1993) and the approach of Eqs. A.18, A.20 based on the method of Richards (1991) for obtaining equivalent neutral winds from the height of the F2 peak electron density was used in the model of the ionosphere and plasmasphere. The $\mathrm{O}^{+}-\mathrm{O}$ collision frequencies given by Salah (1993) and the MSIS-86 model with the adjusted $\mathrm{N}_{2}$ and $\mathrm{O}_{2}$ densities were used in the IZMIRAN model tion frequency of $\mathrm{N}_{2}(j)$ is low (details are given by Pavlov, 1994). This means that for these periods the populations of $\mathrm{N}_{2}(j)$ are less than the populations for a
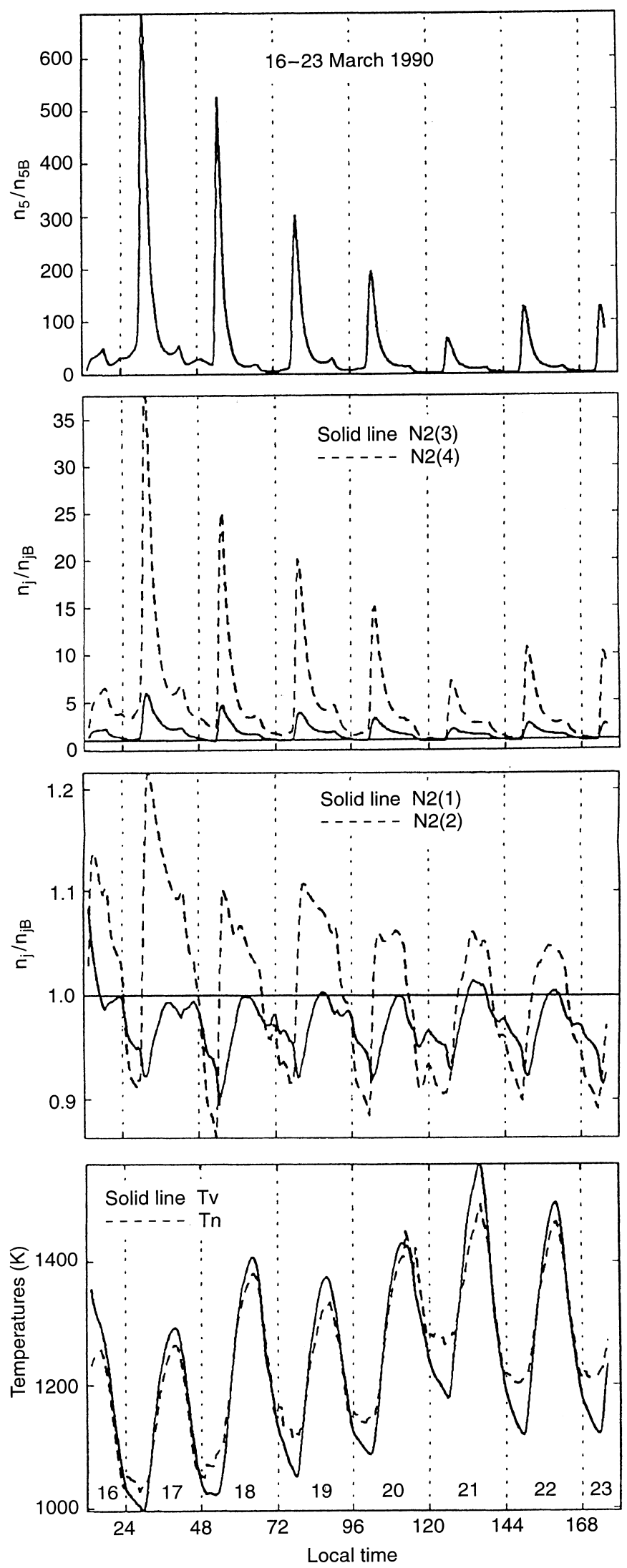
Boltzmann distribution with temperature $T_{n}$. The calculations showed that the vibrational temperature during the quiet period 16-17 March is less than during the magnetic storm period 18-23 March. During the daytime, $T_{v}$ is larger than $T_{n}$, due to the enhanced thermal excitation of $\mathrm{N}_{2}$ as a result of high thermal electron temperatures at F2-region altitudes. On 16-22 March the value of the vibrational temperature was not more than $1600 \mathrm{~K}$.

Figure 1 (solid lines) shows $\mathrm{NmF} 2$ and $\mathrm{hmF} 2$ calculated by using the non-Boltzmann vibrational distribution of $\mathrm{N}_{2}$, and solid and dotted lines of Fig. 3 give the comparison of the modeled densities using the Boltzmann and non-Boltzmann vibrational distribution of $\mathrm{N}_{2}$. It can been seen that the Boltzmann-distribution assumption can lead to an increase in the calculated daytime $\mathrm{NmF} 2$ of up to a factor of 1.1 and to a decrease in the disturbed nighttime $\mathrm{NmF} 2$ by up to a factor of 1.2 in comparison with $\mathrm{NmF} 2$ calculated by using the nonBoltzmann vibrational distribution of $\mathrm{N}_{2}$.

\subsection{EUV Flux}

Figure 5 shows ratios of the measured NmF2(exp) to the modeled NmF2(th) during the 16-23 March 1990 period for the EUVAC solar flux model (solid line) and the EUV94X solar flux model (dashed line). The modeled densities were obtained using the non-Boltzmann vibrational distribution of $\mathrm{N}_{2}$. The method of Eqs. A. 18, A.20 based on the Richards (1991) approach for obtaining equivalent neutral winds from the height of the F2 peak electron density and CEDAR standard (Eqs. 3) for the $\mathrm{O}^{+}-\mathrm{O}$ frequency (Salah, 1993) were used in the model. The model results were obtained when the recombination rate of the $\mathrm{O}^{+}\left({ }^{4} \mathrm{~S}\right)$ ions was multiplied by the factor of 1.5 at all altitudes during the nighttime time-periods of 16-18 March and 19-20 March when the solar zenith angle was more than $90^{\circ}$ in the northern hemisphere.
From Eqs. A.1, A.3-6, it follows that during daytime periods the photoionization frequencies $I_{1}, I_{2}$, and $I_{3}$ for atomic oxygen give a linear relationship between $\mathrm{NmF} 2$ and the solar EUV fluxes. The EUVAC model (Richards et al., 1994a) and the EUV94X model (Tobiska, 1993, 1994) are usually used to calculate the solar EUV fluxes. The ratios of $I_{1}, I_{2}$, and $I_{3}$ given by EUV94X to $I_{1}, I_{2}$, and $I_{3}$ given by EUVAC are $1.52-$ $1.65,1.38-1.48$, and 1.39-1.49, respectively for 16-23 March. Therefore in Fig. 5 the use of EUV94X increases the modeled NmF2 in comparison with NmF2 calculated using EUVAC.

Our model uses analytical formulae to describe the production of $\mathrm{O}^{+}\left({ }^{4} \mathrm{~S}\right), \mathrm{O}^{+}\left({ }^{2} \mathrm{D}\right), \mathrm{O}^{+}\left({ }^{2} \mathrm{P}\right), \mathrm{NO}^{+}, \mathrm{O}_{2}^{+}$, and $\mathrm{N}_{2}^{+}$ions by photoelectron impact (Pavlov, 1994). If the optical depth of the atmosphere goes to zero then production frequencies $I_{1 \mathrm{e}}, I_{2 \mathrm{e}}$ and $I_{3 \mathrm{e}}$ of the $\mathrm{O}^{+}\left({ }^{4} \mathrm{~S}\right), \mathrm{O}^{+}\left({ }^{2} \mathrm{D}\right)$, and $\mathrm{O}^{+}\left({ }^{2} \mathrm{P}\right)$ ions due to photoelectrons can be calculated from Eq. A.7. We found that in this case $I_{1 \mathrm{e}} / I_{1}=0.46-0.47, \quad I_{2 \mathrm{e}} / I_{2}=0.63-0.64, \quad I_{3 \mathrm{e}} / I_{3}$ $=0.65-0.66$ when the EUVAC model fluxes are used and $I_{1 \mathrm{e}} / I_{1}=0.29-0.30, I_{2 \mathrm{e}} / I_{2}=0.44, I_{3 \mathrm{e}} / I_{3}=0.45$ -0.46 when we use EUV94X model fluxes. Therefore the higher photoionization rate using EUV94X compared to EUVAC is partially compensated by the smaller rate of production by photoelectron impact, in agreement with the conclusions of Buonsanto et al. (1995). The resulting effect on the NmF2 is an approximate $10-30 \%$ increase in $\mathrm{NmF} 2$ using the EUV94X model compared to the EUVAC model, and this effect is largest during the daytime periods.

As seen from Fig. 4, the modeled NmF2 are largest when EUV94X is used. The model results obtained using the EUVAC flux model agree a little better with the observations in comparison with using the EUV94X flux model. If we use the EUVAC model, then in general the Boltzmann vibrational $\mathrm{N}_{2}$-distribution assumption gives better agreement between measured and modeled $\mathrm{NmF} 2$ than the non-Boltzmann vibrational distribution of $\mathrm{N}_{2}$. To improve this agreement in the ionospheric

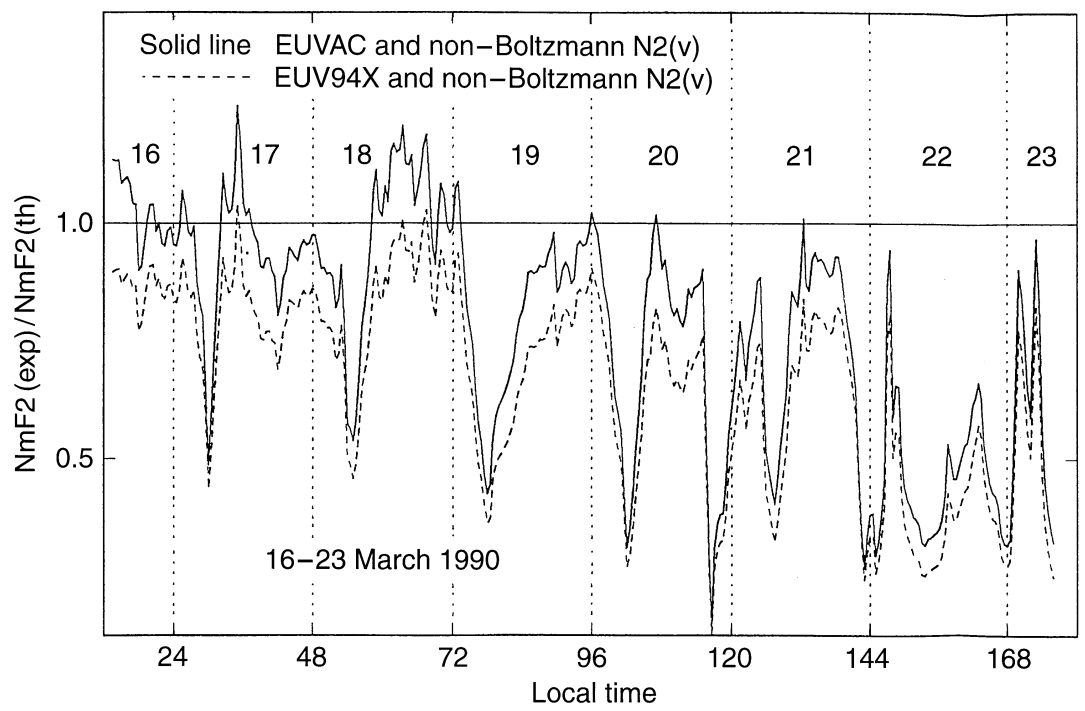

Fig. 5. Ratios of the measured $\mathrm{F} 2$ peak densities $\mathrm{NmF} 2(\exp )$ to the modeled F2 peak densities NmF2(th) during the 16-23 March 1990 period for the EUVAC solar flux model ( solid line) and the EUV94X solar flux model (dashed line). The modeled NmF2 were obtained using the nonBoltzmann populations of the first five vibrational levels by solving the $\mathrm{N}_{2}(v=1-5)$ time-dependent continuity equations, the $\mathrm{O}^{+}-\mathrm{O}$ collision frequencies given by Salah (1993), and the MSIS-86 model with adjusted recombination rate of the $\mathrm{O}^{+}\left({ }^{4} \mathrm{~S}\right)$ ions 
model with EUV94X fluxes, the non-Boltzmann vibrational distribution of $\mathrm{N}_{2}$ is needed.

\subsection{Electron and ion temperatures}

Figure 6 shows the diurnal variations of the measured (solid lines) and modeled (dashed and dotted lines) electron and ion temperatures at the F2 peak altitude for the EUVAC solar flux model. The $\mathrm{O}^{+}-\mathrm{O}$ frequencies given by Salah (1993) and the method of Eqs. A.18, A.20 based on the Richards (1991) approach for obtaining equivalent neutral winds from the height of the F2 peak electron density and the adjustment of the recombination rate of the $\mathrm{O}^{+}\left({ }^{4} \mathrm{~S}\right)$ ions was used in the model of the ionosphere and plasmasphere. The model results were obtained using the non-Boltzmann vibrational $\mathrm{N}_{2}(v)$ distribution (dashed lines), and when $\mathrm{N}_{2}(v)$ was not included in the loss rate of the $\mathrm{O}^{+}\left({ }^{4} \mathrm{~S}\right)$ ions (dotted line). As can be seen, the effects on $T_{e}$ of adding $\mathrm{N}_{2}$ (v) are largest during the day, with increases in $T_{e}$ accompanying the decreases in $\mathrm{NmF} 2$, improving the agreement with observations.
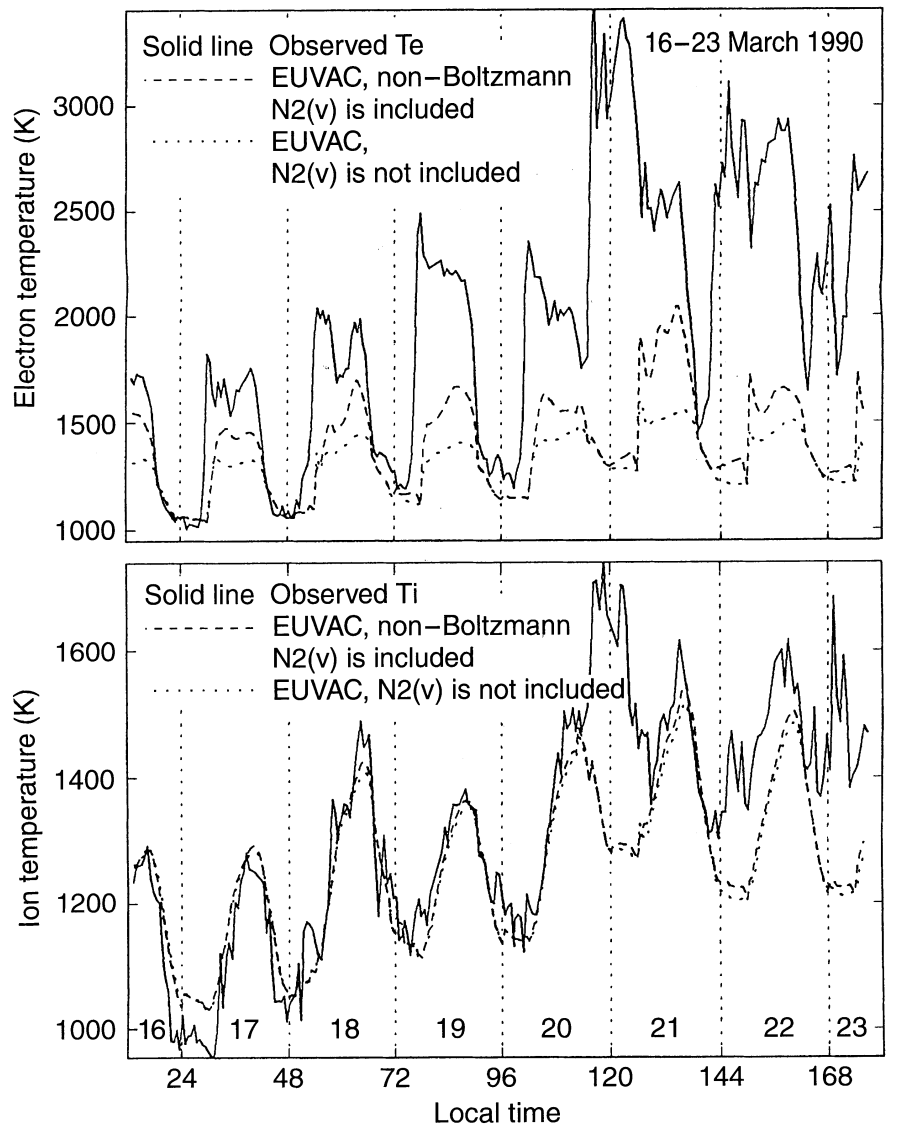

Fig. 6. The measured (solid lines) and modeled (dashed and dotted lines) electron (top) and ion (bottom) temperatures at the F2 peak altitude on 16-23 March 1990 for the EUVAC solar flux model. The dashed lines show results when the non-Boltzmann populations of the first five vibrational levels of $\mathrm{N}_{2}(v)$ are included in the model, and the dotted lines are ones without the effects of vibrationally excited $\mathrm{N}_{2}$ on the loss rate of the $\mathrm{O}^{+}\left({ }^{4} \mathrm{~S}\right)$ ions
During the period 16-18 March the agreement between the measured and modeled temperatures is excellent except during the short time-periods around 5.00-7.00 LT for the electron temperature. These measured short-duration electron-temperature enhancements near these sunrise regions were not described by the model. On 19 March the agreement is satisfactory for the electron temperature and is good for the ion temperature. The modeled electron temperatures are generally lower than the measured electron temperatures after the 20 March storm. The electron-ion cooling rate is proportional to the square of the electron density, and therefore if the electron density is too large, then the electron temperature is too small, as is apparent during the day for 19 and 22 March. When $\mathrm{N}_{2}(v)$ is not included in the loss rate of the $\mathrm{O}^{+}\left({ }^{4} \mathrm{~S}\right)$ ions, the agreement between the model and the data worsens. From our calculations it follows that the use of the EUVAC flux model gives better agreement between measured and modeled electron temperatures than the EUV94X flux model, because the modeled electron temperatures are higher as a consequence of the modeled NmF2 being lower (see Fig. 5). The effects of the flux model and $\mathrm{N}_{2}(v)$ on the calculation of $\mathrm{T}_{\mathrm{i}}$ are not very large.

\subsection{FLIP and IZMIRAN models- data comparisons}

Richards et al. (1994b) compared observed values of $\mathrm{NmF} 2, \mathrm{hmF} 2, T_{e}$, and $T_{i}$ at Millstone Hill with FLIP model results for the March 1990 storm. Unlike the results shown in Fig. 1, calculations with the FLIP model without including $\mathrm{N}_{2}(v)$ gave good agreement with the data on 18-20 March. However, the inclusion of $\mathrm{N}_{2}(v)$ improved the agreement with the data during the disturbed period 21-23 March.

The FLIP and the IZMIRAN models are very similar models of the thermal plasma in the ionosphere and plasmasphere. Both solve the coupled time-dependent energy, momentum, and continuity equations for major ions and electrons, and photoelectron transport equations from the base altitude in both hemisphere, along a field line to the same base altitude in the other hemisphere.

Both the FLIP model and the IZMIRAN model use the theoretical interpretation of the flow-drift tube measurements of the recombination-rate coefficient of $\mathrm{O}^{+}\left({ }^{4} \mathrm{~S}\right)$ ions with $\mathrm{N}_{2}(v=0)$ (Albritton et al., 1977) and formulas for the dependence of this rate coefficient of the effective temperature given by St.-Maurice and Torr (1978). For vibrationally excited $N_{2}$, the FLIP model uses only the recombination-rate coefficients of $\mathrm{O}^{+}\left({ }^{4} \mathrm{~S}\right)$ ions with $N_{2}(v>0)$ measured by Schmeltekopf et al. (1968) only for $T_{n}=T_{i}=300 \mathrm{~K}$. The IZMIRAN model uses theoretical formulas given by Pavlov (1988) based on the measurements of Schmeltekopf et al. (1968). The temperature dependence given by Van Zandt and O'Malley (1973) determines the dependence of these rate coefficients on the effective temperature in the IZMIRAN model. In the FLIP model $\mathrm{K}_{1}(\mathrm{~T}) / \mathrm{K}_{0}(\mathrm{~T})=1, \mathrm{~K}_{2}(\mathrm{~T}) /$ 
$\mathrm{K}_{0}(\mathrm{~T})=38, \quad \mathrm{~K}_{3}(\mathrm{~T}) / \mathrm{K}_{0}(\mathrm{~T})=85, \quad \mathrm{~K}_{4}(\mathrm{~T}) / \mathrm{K}_{0}(\mathrm{~T})=220$, $\mathrm{K}_{5}(\mathrm{~T}) / \mathrm{K}_{0}(\mathrm{~T})=270$ where $\mathrm{T}$ is the effective temperature.

The heated drift tube measurements of the recombination-rate coefficient of $\mathrm{O}^{+}\left({ }^{4} \mathrm{~S}\right)$ ions with $\mathrm{O}_{2}, \gamma$, given by Chen et al., (1978) are systematically lower than the flow-drift tube measurements, $\gamma_{\mathrm{E}}$, of this rate coefficient Albritton et al., 1977. In an attempt to reconcile the two sets of measurements, the IZMIRAN model (Pavlov, 1993) uses $\gamma=\gamma_{\mathrm{E}} \exp \left(-8.53 .10^{-4} T_{n}+0.315\right)$ with the approximation for $\gamma_{\mathrm{E}}$ given by St.-Maurice and Torr (1978). Torr et al. (1990) normalized the drift tube date of Albritton et al. (1977) on the results of Chen et al. (1978) at $700 \quad \mathrm{~K}$ and obtained $\gamma=2.1 \cdot 10^{-11}$ $\left(T_{n}+2 T_{i} / 3 \times 300\right)^{-0.763} \mathrm{~cm}^{3} \mathrm{~s}^{-1}$ which is used in the FLIP model.

The quenching of $\mathrm{O}^{+}\left({ }^{2} \mathrm{D}\right)$ by atomic oxygen is assumed to be $10^{-10} \mathrm{~cm}^{3} \mathrm{~s}^{-1}$ (Oppenheimer et al., 1976; Fox and Dalgarno, 1985) in the IZMIRAN model and $5 \cdot 10^{-12}$ (Abdou et al., 1984) in the FLIP model. These rate coefficients were obtained from agreement between the measured and model densities of $\mathrm{N}_{2}^{+}$and the different points of view were discussed by Torr and Torr (1982), Abdou et al., (1984), Ferguson (1984), and Fox and Dalgarno (1985). This discussion illustrates that laboratory measurements of this rate coefficient are highly desirable.

The FLIP model solves the two-stream photoelectron Liouville equations to calculate the photoelectron fluxes, and these fluxes are used to find the heating rate of the electron gas by photoelectrons and the rate of ionization by secondary photoelectrons. In the IZMIRAN model, electron heating due to photoelectrons is provided by a solution of the Boltzmann equation for photoelectron flux using the method of Krinberg and Tashchilin (1984). The IZMIRAN model uses the approximative approach of Pavlov (1994) to calculate the rate of ionization by secondary photoelectrons.

These differences between the FLIP model and the IZMIRAN model give the differences in the model results for the March 1990 magnetic storm.

\section{Undisturbed period and storms of 6-12 April 1990}

The undisturbed conditions of 6-8 April 1990 and the 9-12 April 1990 magnetic storms were periods of moderate solar activity, when the 10.7 solar flux varied between 146 and 169 and $A_{p}$ between 6 and 124. During the April 1990 period, two geomagnetic storms took place with sudden commencement times near 0842 UT on 9 April and 0325 UT on 12 April. The measured electron densities and temperatures and ion temperatures used in this paper were taken by the incoherent-scatter radar at Millstone Hill, Massachusetts (Buonsanto et al., 1992a).

Figure 7 is a plot of the measured hmF2 and NmF2 for the period 6-12 April 1990 and the model results which will be discussed later. The model results have been obtained from the mathematical model with the $\mathrm{O}^{+}-O$ collision frequencies given by Salah (1993), the original MSIS-86 model, and the approach of Eqs. A.18,
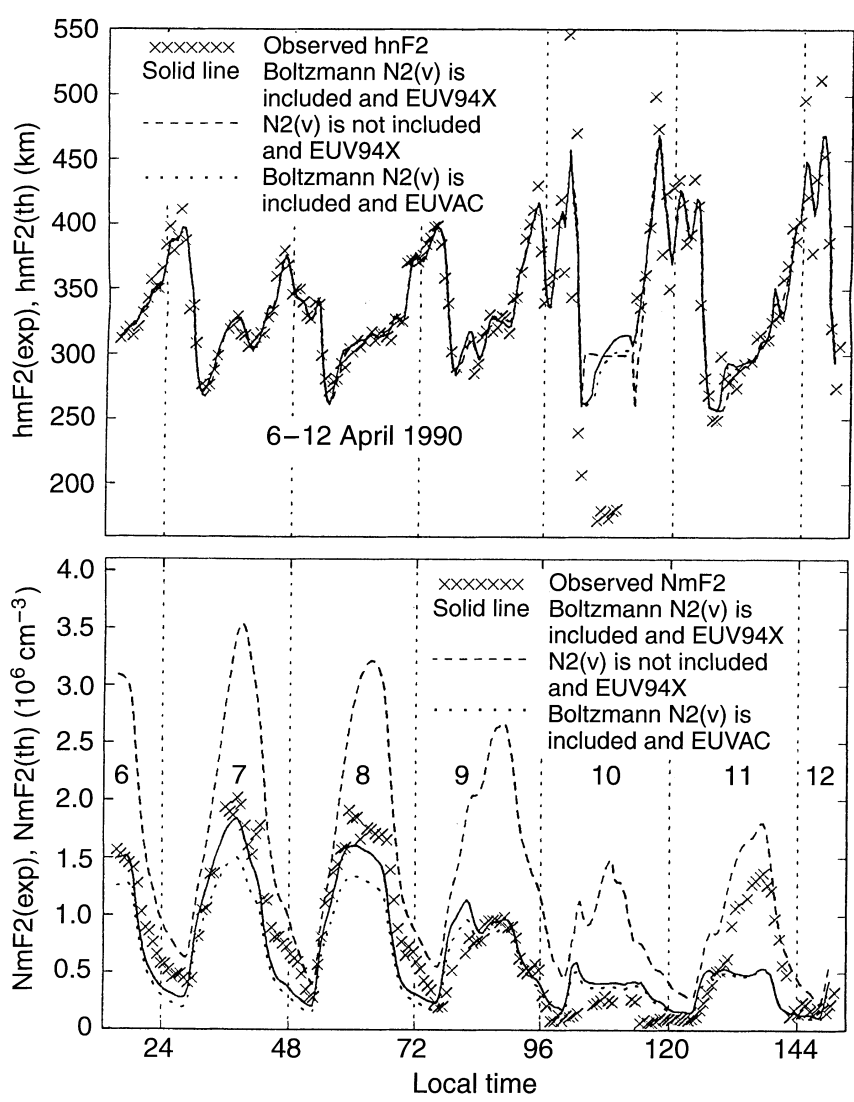

Fig. 7. Observed (crosses) and calculated F2 peak parameters above Millstone Hill for the magnetically quiet and disturbed period 6-12 April 1990 for the EUV94X solar flux model (solid and dashed lines) and the EUVAC solar flux model (dotted lines). The solid and dotted lines are $\mathrm{hmF} 2$ and $\mathrm{NmF} 2$ from the IZMIRAN model when the Boltzmann populations of the first five vibrational levels of $\mathrm{N}_{2}(v)$ are included in the calculated $\mathrm{O}^{+}\left({ }^{4} \mathrm{~S}\right)$ recombination rate, and dashed are $\mathrm{hmF} 2$ and $\mathrm{NmF} 2$ when $\mathrm{N}_{2}(v)$ is not included in the calculations

A.20 based on the improved algorithm given by Richards (1991).

Unlike the March period, there are only negative phases in the measured NmF2 compared to the undisturbed period of 6-7 April. The most notable feature of this period is the disappearance of the F2 peak on 10 April, when the peak height of the electrondensity maximum dropped to $180 \mathrm{~km}$.

In modeling the April magnetic storm we also used the theoretical formulae of the $1-3$ for the $\mathrm{O}^{+}-\mathrm{O}$ collision freqency. Like the results of March in Fig. 2, the Salah (1993) collision frequency resulted in NmF2 which were approximately $5-17 \%$ larger than those calculated using the Banks (1966) formulae. Again, the Salah (1993) formulae gave the best agreement between measured and modeled NmF2.

Figure 7 shows that similar to the March period, the EUV94X model (solid lines) produced the largest electron densities, increasing NmF2 by about $10-40 \%$ compared to the EUVAC model (dotted lines). Unlike the March period, for the period 6-9 April 1990 the EUV94X model results agree better with the observations in comparison to using the EUVAC model. 
Like the 17-18 March and 19-20 March period, on 6-9 April the nighttime measured densities were a factor of up to 1.5-2 larger than the model densities. There may be an unidentified physical or chemical process that has not been included in the IZMIRAN model. It is possible that this nighttime discrepancy between measured and modeled $\mathrm{NmF} 2$ is caused by inaccuracies in key inputs, such as the composition and temperature of the neutral atmosphere, and the recombination-rate coefficients of $\mathrm{O}^{+}\left({ }^{4} \mathrm{~S}\right)$ ions with $\mathrm{N}_{2}(\mathrm{j}=0-5)$ and $\mathrm{O}_{2}$. From our calculations it follows that in order to reproduce the observed nighttime NmF2 on 6-10 April the recombination rate of $\mathrm{O}^{+}\left({ }^{4} \mathrm{~S}\right)$ ions needs to decrease by a factor of 1.5 at all altitudes during the nighttime 6-7 April, 7-8 April, and 9-10 April periods when the solar zenith angle was more than $90^{\circ}$ in the northern hemisphere.

The method of Eqs. A.18, A.20 reproduces well the measured $\mathrm{hmF} 2$ during the quiet and disturbed periods on 6-9 April except for the unusually large fluctuations in peak height such as occurred on 10 April. The method of deriving the equivalent neutral wind from the observed hmF2 does not work if the peak layer is in the F1 region. Also, the equivalent winds will be contaminated with any large electric fields such as were present at the beginning and end of the disappearance of the F2 layer (Buonsanto et al., 1992a; see also Fig. 10. discussed later). On 9-11 April the theoretical $\mathrm{NmF} 2$ sometimes describes the experimental data well, but often the calculated $\mathrm{NmF} 2$ differs greatly from the measured $\mathrm{NmF} 2$. Some reasons for these disagreements are that we do not take into account the effect of electric fields on the ionosphere and the MSIS model does not predict neutral densities and temperature accurately during some geomagnetic storms. The effects of the electric fields on the electron density and the ion temperature are presented in the next section.

Figure 7 (bottom panel) shows that the modeled peak densities without effects of vibrationally excited $\mathrm{N}_{2}(v)$ (dashed line) are much larger than the modeled peak densities with $\mathrm{N}_{2}(v)$ (solid line). Both the daytime and nighttime measured densities are not reproduced by the model without $\mathrm{N}_{2}(v)$. On 6-12 April this effect of $\mathrm{N}_{2}(v)$ on $\mathrm{NmF} 2$ is up to a factor of about 3.5 reduction, similar to the case for the March period. In both March and April magnetic storms, the effect of vibrationally excited $\mathrm{N}_{2}$ on $N_{e}$ and $T_{e}$ is most pronounced during the daytime.

In modeling the April magnetic storm we also calculated deviations from the Boltzmann distribution of $\mathrm{N}_{2}(v)$. Like the results of March in Fig. 4, the real distribution is highly non-Boltzmann at the vibrational levels $\mathrm{j}>2$ and the deviations from the Boltzmann distribution are not significant at the first and second vibrational levels of $\mathrm{N}_{2}$. Nevertheless, the values of the relative deviations $n_{3} / n_{3 \mathrm{~B}}<3.2$ and $n_{4} / n_{4 \mathrm{~B}}<17$. The deviations on third and fourth vibrational levels of $\mathrm{N}_{2}$ have their maximum values during the period $6.30-7.30$ LT. The April variations of the calculated vibrational temperature are very similar to that for Millstone Hill on March 1990. Similar to the March case, the
Boltzmann-distribution assumption can lead to a 10$20 \%$ increase in the calculated NmF2 in comparison with NmF2 calculated using the non-Boltzmann vibrational distribution of $\mathrm{N}_{2}$.

The diurnal variations of the measured (solid lines) and modeled (dashed and dotted lines) electron and ion temperatures at the F2 peak altitude are shown in Fig. 8. The $\mathrm{O}^{+}-\mathrm{O}$ frequencies given by Salah (1993) and the method of Eqs. A.18, A.20 for obtaining equivalent neutral winds from the height of the F2 peak electron density were used in the model of the ionosphere and plasmasphere. The model results were obtained using the EUV94 solar flux model with the Boltzmann vibrational $\mathrm{N}_{2}$ distribution (dashed lines) and when $\mathrm{N}_{2}(v)$ is not included in the loss rate of the $\mathrm{O}^{+}\left({ }^{4} \mathrm{~S}\right)$ ions (dotted line). The modeled ion temperatures with the Boltzmann vibrational $\mathrm{N}_{2}$ distribution are about the same as when $\mathrm{N}_{2}(v)$ is not included.

During the quiet and disturbed period 6-9 April the agreement between the measured and modeled temperatures is excellent except for the time period 4.30-6.00 LT for the electron temperature. This measured, shortduration electron-temperature enhancement near the sunrise region was not described by the model. Electric
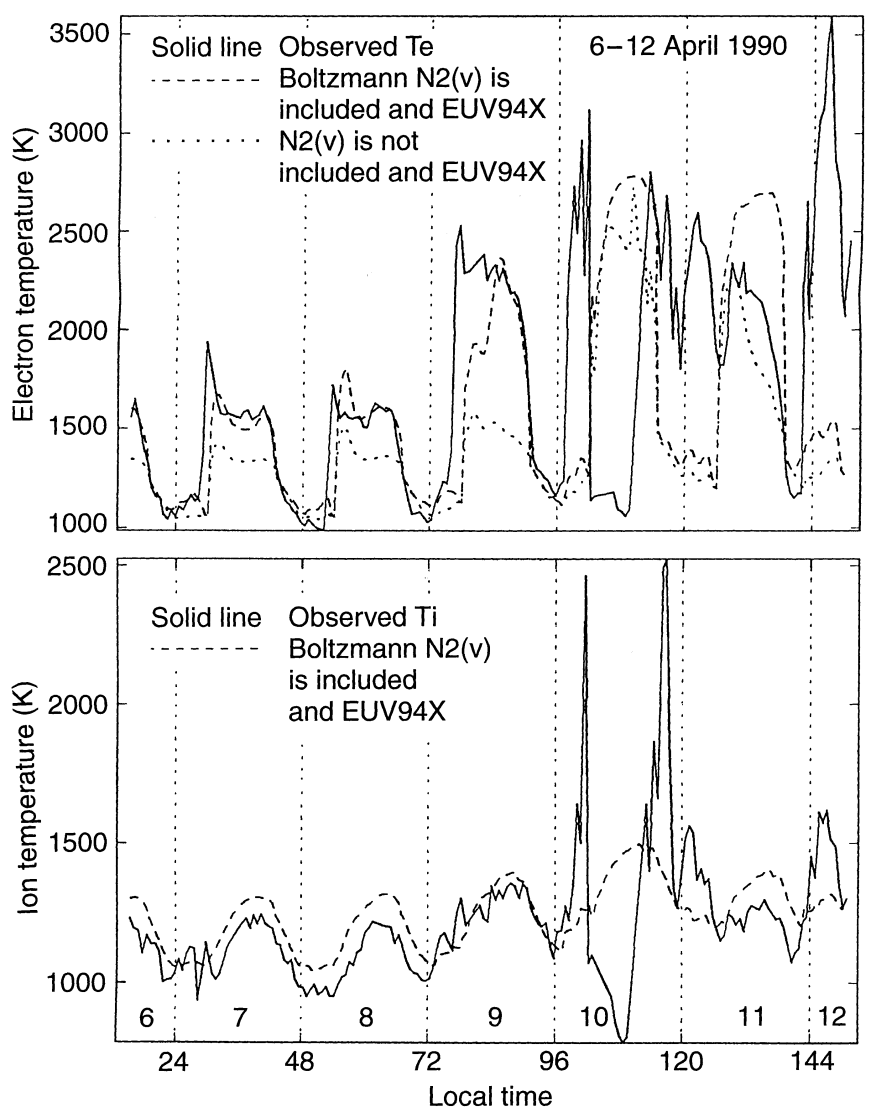

Fig. 8. The measured (solid lines) and modeled (dashed and dotted lines) electron (top) and ion (bottom) temperatures at the F2 peak altitude 6-12 April 1990 for the EUV94X solar flux model. The dashed lines show results when the Boltzmann populations of the first five vibrational levels of $\mathrm{N}_{2}(v)$ are included in the model and the dotted line is one without effects of vibrationally excited $\mathrm{N}_{2}$ on the loss rate of the $\mathrm{O}^{+}\left({ }^{4} \mathrm{~S}\right)$ ions 
fields larger than $30 \mathrm{mV} / \mathrm{m}^{-1}$ were present around 6 and 18 LT on 10 April and also during the first part of 12 April when the modeled ion and electron temperatures are significantly smaller than the observations. The large model ion and electron temperatures, during the middle of the day on 10 April reflect the fact that they are F2region temperatures, while the observations are in the F1 region with the disappearance of the $\mathrm{F} 2$ electron density peak. When $\mathrm{N}_{2}(v)$ is not included in the loss rate of the $\mathrm{O}^{+}\left({ }^{4} \mathrm{~S}\right)$ ions, the agreement between the model and the data worsens in comparison with its inclusion, with the exception of the daytime period on 10 April when the measured peak electron density was in the F1 region.

\section{Effect of measured electric fields and meridional neutral winds on electron density}

The short-lived electric fields produce significant effects on $N_{e}$ and the ion temperature, $T_{i}$ (Schunk et al., 1975; Raitt et al., 1976). These changes in the electron density and ion temperature are the reason for the electrontemperature disturbances. These electric fields were stronger during the April 1990 storm than during the March 1990 storm at Millstone Hill (Buonsanto et al., 1992a).

The values of perpendicular electric fields $E_{\perp}$ (with respect to $\boldsymbol{B}$ ) and meridional neutral winds were measured during the March and April 1990 magnetic storms (Buonsanto et al., 1992a). Using these measured neutral winds we can calculate the wind-induced plasma drift velocity in the direction along a magnetic field line as $W_{d}=U_{\theta} \cos I$, where $I$ is the magnetic field dip angle, $U_{\theta}$ is the component of thermospheric wind in spherical polar coordinates, and $\theta$ is the geomagnetic colatitude. After that we can use these $W_{d}$ as input data in the model of the thermal plasma in the ionosphere and plasmasphere.

We use two important changes of the IZMIRAN model given by Pavlov (1996) to take into account the effect of $E_{\perp}$ on $N_{c}$ and $T_{i}$. To model the effect of $E_{\perp}$ on $T_{i}$ we added the local ion-heating rate due to perpendicular electric fields, $Q_{i \perp} \sim E_{\perp}^{2}$, given by Schunk et al. (1975) in the ion-energy equation of the IZMIRAN model. The rate coefficients of the important ionospheric processes such as the reaction of $\mathrm{O}^{+}\left({ }^{4} \mathrm{~S}\right)$ with $\mathrm{N}_{2}$ and $\mathrm{O}_{2}$ depend on the effective temperature which is a function of the ion temperature, the neutral temperature, and the plasma drift velocity (Albritton et al., 1977; Viehland and Mason, 1977; St.-Maurice and Torr, 1978; Pavlov, 1988). The plasma drift velocity is resolved into components parallel and perpendicular to the geomagnetic field, $\boldsymbol{B}$, with the perpendicular component

$$
\boldsymbol{V}_{\perp}=(\boldsymbol{E} \times \boldsymbol{B}) / \boldsymbol{B}^{2},
$$

where $\boldsymbol{E}$ is the electric field.

This dependence of the recombination rate of $\mathrm{O}^{+}\left({ }^{4} \mathrm{~S}\right)$ ions on $\mathrm{E}_{\perp}$ gives the effect of $\mathrm{E}_{\perp}$ on $N_{e}$.

In Figs. 9-10 we present the measured hmF2 and $\mathrm{NmF} 2$, the measured $\mathrm{E}_{\perp}$ at the hmF2 altitude (Buon- santo et al., 1992a), and the model results during the 1623 March and 6-8 April 1990 periods. The dashed lines show the results when we used in the model without $\mathrm{E}_{\perp}$ the algorithm (Eqs. A.1, A.20) for obtaining equivalent neutral winds from the height of the F2 peak electron density, whereas the dotted lines were obtained when the measured $\mathrm{E}_{\perp}$ and meridional neutral winds were used.

From Figs. 9 and 10, the observed hmF2 s are generally lower during the day and the night, except for the very brief nighttime periods 17-22 March and 10-12 April compared to the hmF2 s derived using measured $\mathrm{E}_{\perp}$ and the meridional neutral wind. Figures 9 and 10 show that the effect of using $E_{\perp}$ and the meridional neutral wind instead of the measured hmF2 results in higher values of $\mathrm{NmF} 2$ both day and night, and in higher values of hmF2 during the most part of the 16-23 March and 6-8 April periods. Since using the measured hmF2 often results in nighttime $\mathrm{NmF} 2$ values which are too low compared to observations, this often means that using the $\mathrm{E}_{\perp}$ and meridional neutral wind results in better nighttime agreement during the March storm. However, the values during the day are usually higher than the observations and the results using hmF2 observations. Since using the data does not always give theoretical values that agree better with other observations such as $\mathrm{NmF} 2$, there are other sources of uncertainty, such as the model input parameters, physical processes, and errors in the measurements.

For the April storm Fig.10 also gives the measured $T_{i}$ at the hmF2 altitude (Buonsanto et al., 1992a) and the calculated $T_{i}$. As can be seen, the effects using $\mathrm{E}_{\perp}$ and the meridional neutral wind instead of the measured hmF2 on $T_{i}$ are largest on 10 April with increases in $T_{i}$ up to about $230 \mathrm{~K}$, making worse the agreement with observations during the middle of the day on 10 April because the modeled $T_{i}$ are F2-region ion temperatures, while the measured $T_{i}$ are the F1-region ion temperatures. For the March storm these increases in $T_{i}$ are less than $50 \mathrm{~K}$.

Extremely low NmF2 and hmF2 (rather, it was the F1 peak) were observed between 9.30 and 14.30 LT on 10 April (Buonsanto et al., 1992a). Our calculations indicate that the electron density, decreases if the electric-field strength increases due to the increased rates of the reactions $\mathrm{O}^{+}\left({ }^{4} \mathrm{~S}\right)$ with $\mathrm{N}_{2}$ and $\mathrm{O}_{2}$ relative to the zero electric field result while the $\mathrm{NO}^{+}$and $\mathrm{O}_{2}^{+}$ densities are increased. For $E_{\perp} \sim 90-100 \mathrm{mV} \mathrm{m}^{-1}$, the decrease in $\mathrm{O}^{+}\left({ }^{4} \mathrm{~S}\right)$ ion density is sufficient to cause the density of molecular ions to be greater than the $\mathrm{O}^{+}\left({ }^{4} \mathrm{~S}\right)$ ion density. As a result the usual F2 region peak created by $\mathrm{O}^{+}\left({ }^{4} \mathrm{~S}\right)$ ions vanishes, the new $\mathrm{F} 2$ region peak (rather it is the F1 peak) due to molecular ions results, and the extremely low observed $\mathrm{NmF} 2$ and $\mathrm{hmF} 2$ can be explained. However, $E_{\perp} \sim 90-100 \mathrm{~m} \mathrm{~V} \mathrm{~m}^{-1}$ were not observed between 9.30 and 14.30 LT on 10 April (Buonsanto et al., 1992a) and therefore the model was unable to account for the observed NmF2 and hmF2.

Data show a decrease in the electric fields around midday, but the larger electric fields in the morning may have produced some longer-lasting changes in the neutral temperature and the neutral composition, which 

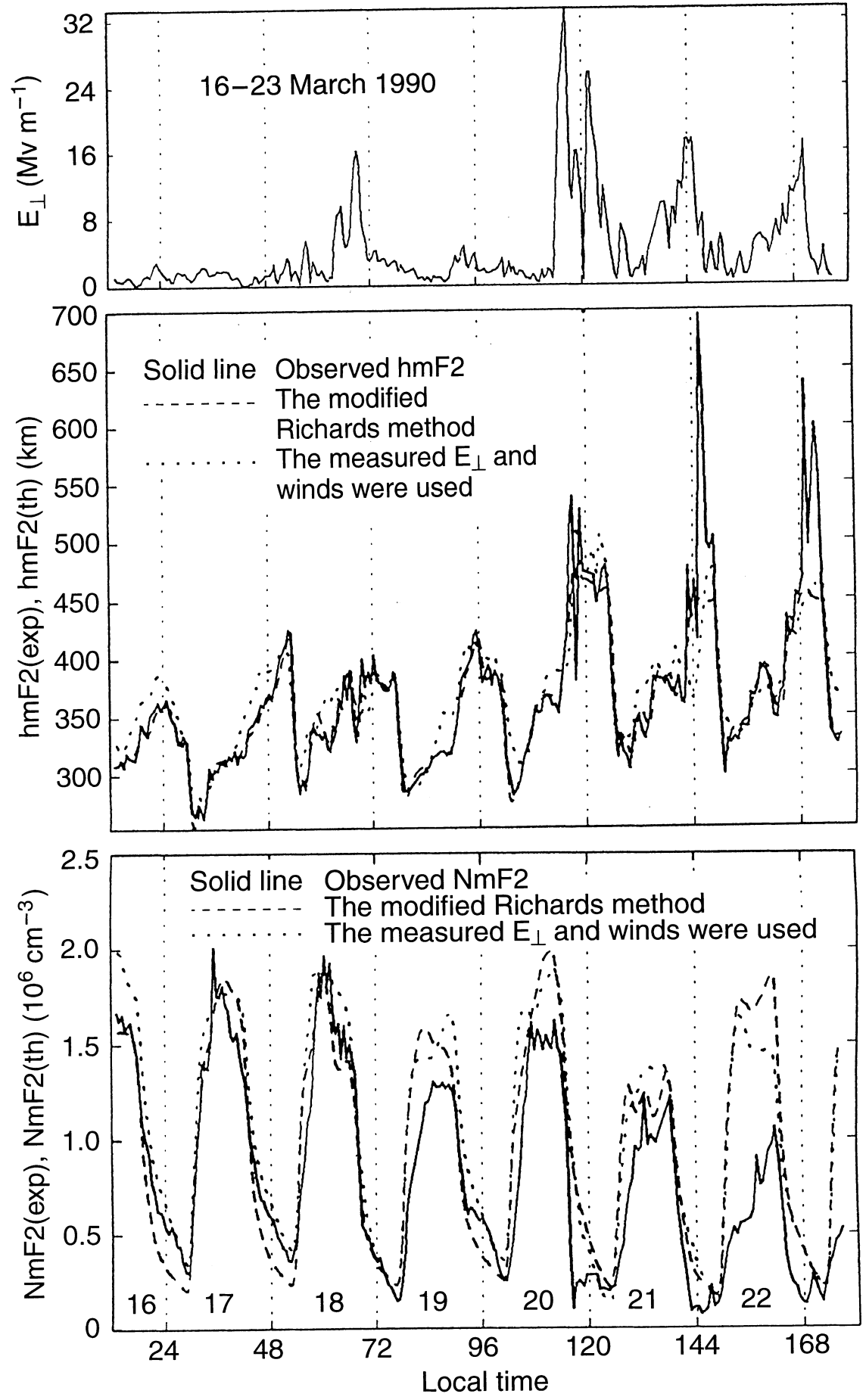

Fig. 9. The measured $E_{\perp}$ at the $h m F 2$ altitude (top panel), the measured and modeled hmF2 (middle panel), and the measured and modeled NmF2 (bottom panel) during the 16-23 March 1990 period for the EUVAC solar flux model. The solid lines are the Millstone Hill data (Buonsanto et al., 1992a). The dotted lines show the results when we use no $\mathrm{E}_{\perp}$ in the model and the approach based on the method of Richards (1991) for obtaining equivalent neutral winds from the height of the F2 peak electron density, whereas the dashed lines were obtained when the measured $\mathrm{E}_{\perp}$ and meridional neutral winds were used. All the model results have been obtained from the IZMIRAN model with the Boltzmann populations of the first five vibrational levels of $\mathrm{N}_{2}(v)$, the $\mathrm{O}^{+}-\mathrm{O}$ frequencies given by Salah (1993) and the original recombination rate of $\mathrm{O}^{+}\left({ }^{4} \mathrm{~S}\right)$ ions are not included in the MSIS- 86 model, and as a result the modeled $N_{e}$ may be larger than the data near midday on 10 April. Another explanation of the disagreement between the modeled $N_{e}$ and the data on 10 April is that this plasma depletion in the flux tube with extremely low $\mathrm{NmF} 2$ and hmF2 can be created in the mid-latitude trough by horizontal plasma convection. To model this transfer of plasma, caused by some plasmaspheric electric field (usually of magnetospheric origin), consideration of the perpendicular divergence contribution in the ion equations of continuity arising from horizontal plasma gradients is needed, and a model of this electric field is required or must be created. We intend to solve these tasks in future studies by the development of the IZMIRAN model.

\section{Forecast of $\mathrm{NmF2}$ and $\mathrm{hmF2}$ during magnetic storms}

In modeling electron densities it is important to reproduce $\mathrm{hmF} 2$ which is primarily influenced by the neutral wind. Richards (1991) developed an algorithm 
that ensures a close reproduction of the observed $\mathrm{hmF} 2$ by a time-dependent model. Ideally, the observed $\mathrm{hmF} 2$
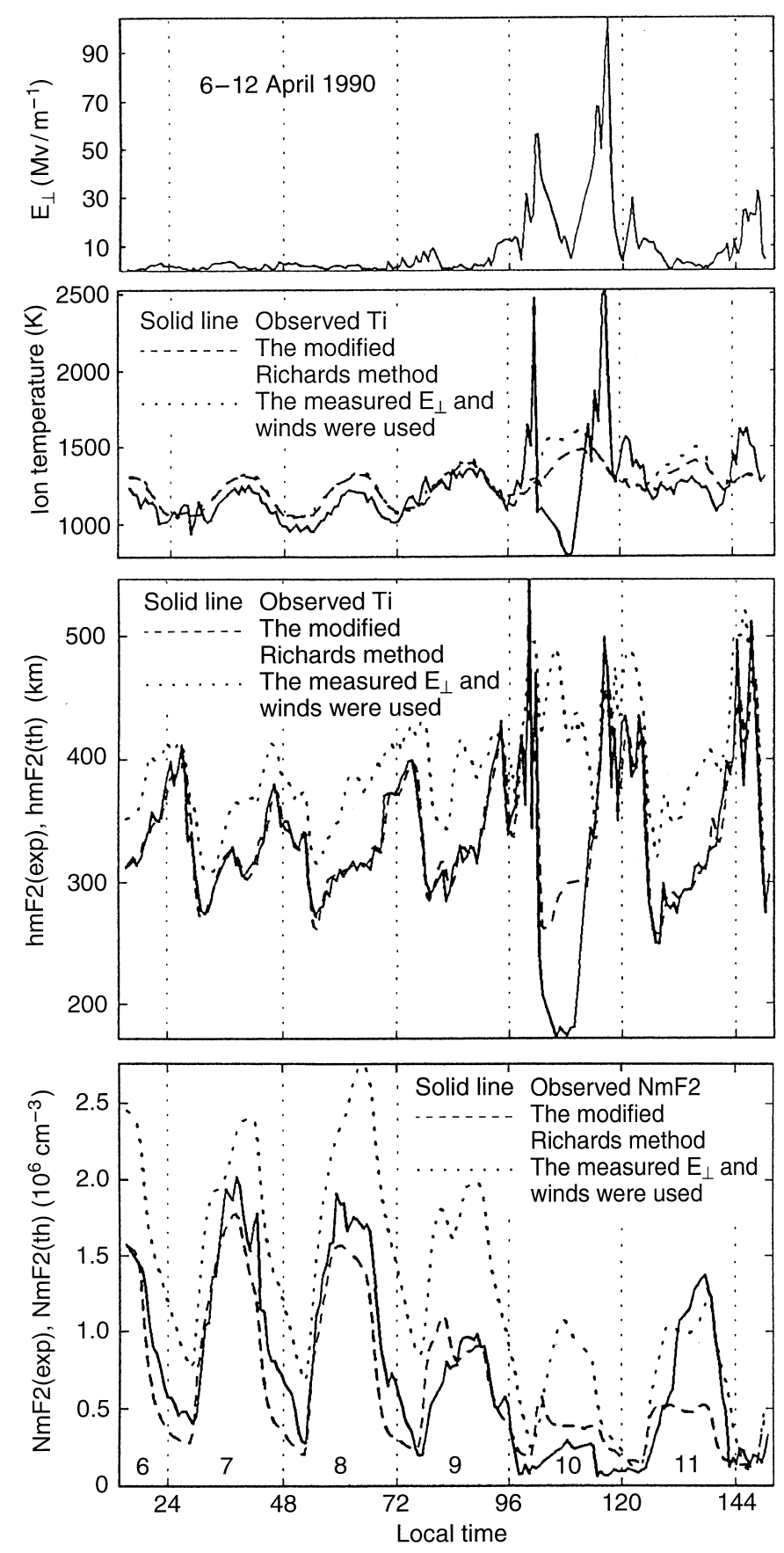

Fig. 10. The measured $\mathrm{E}_{\perp}$ at the hmF2 altitude (top panel), the measured and modeled $T_{i} \mathrm{hmF} 2$ (two middle panels), and the measured and modeled NmF2 (bottom panel) during the 6-12 April 1990 period for the EUV94X solar flux model. The solid lines are the Millstone Hill data (Buonsanto et al., 1992a). The dotted lines show the results when we use in the model no $\mathrm{E}_{\perp}$ and the approach based on the method of Richards (1991) for obtaining equivalent neutral winds from the height of the F2 peak electron density, whereas the dashed lines were obtained when the measured $\mathrm{E}_{\perp}$ and meridional neutral winds were used. All the model results have been obtained from the IZMIRAN model with the Boltzmann populations of the first five vibrational levels of $\mathrm{N}_{2}(v)$, the $\mathrm{O}^{+}-\mathrm{O}$ frequencies given by Salah (1993), and the original recombination rate of $\mathrm{O}^{+}\left({ }^{4} \mathrm{~S}\right)$ ions should be available for several hours before the time of the comparison, but very often only a limited set of $\mathrm{hmF} 2$ measurements is available or we have not got the observed $\mathrm{hmF} 2$, To overcome this problem, we can use Eqs. A.21-23 to calculate equivalent plasma drift velocities during geomagnetic storms.

Figures 11 and 12 represents the modeled $h m F 2$ and $\mathrm{NmF}$ (the solid lines) obtained when this approach was used. For both the March and April magnetic storms the errors in the prediction of the modeled $\mathrm{NmF} 2$ are about the same as when we use the measured $\mathrm{hmF} 2$ and the Richards (1991) method with our modification A.18, A.20 to calculate an equivalent plasma drift velocity. In our approach (Eqs. A.21-A.23), the measured and modeled daytime $\mathrm{hmF} 2$ agreed better than the nighttime $\mathrm{hmF} 2$. The disagreement between the measured and calculated hmF2 is not more than $14,36,63,41,144,64$, 264, and $184 \mathrm{~km}$ on the nights of March 16-23, and not more than $9,19,40,27,19,56,28$, and $36 \mathrm{~km}$ on days of 16-23. On the nights of 8-12 April the disagreement between the measured and calculated $\mathrm{hmF} 2$ is not more than $22,58,204,43$, and $78 \mathrm{~km}$, and not more than 15 , 50,121 , and $75 \mathrm{~km}$ on days of $8-11$.
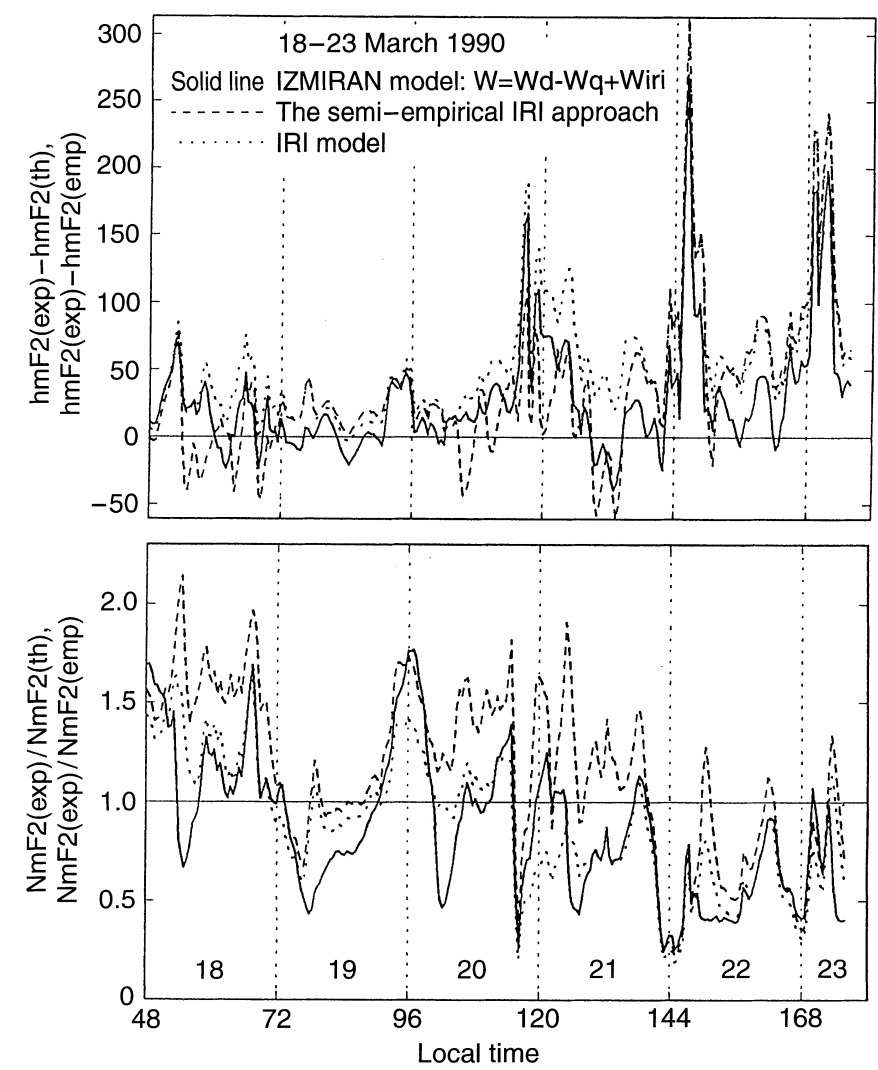

Fig. 11. Comparison of measured $\mathrm{NmF} 2(\exp )$ and $\mathrm{hmF} 2(\exp )$ with peak densities and heights $\mathrm{NmF}$ 2(th) and $\mathrm{hmF}$ 2(th) given by the IZMIRAN model with algorithm Eq. A.23 (the solid lines) and $\mathrm{NmF} 2(\mathrm{emp})$ and hmF2(emp) given by the IRI-90 model (the dotted lines) and by the semiemprical IRI approach described by Kishcha (1995) (the dashed lines) for the disturbed period of 18-23 March 1990. The Boltzmann vibrational distribution of $\mathrm{N}_{2}(v)$, and the original recombination rate of $\mathrm{O}^{+}\left({ }^{4} \mathrm{~S}\right)$ ions are implied in the IZMIRAN model 

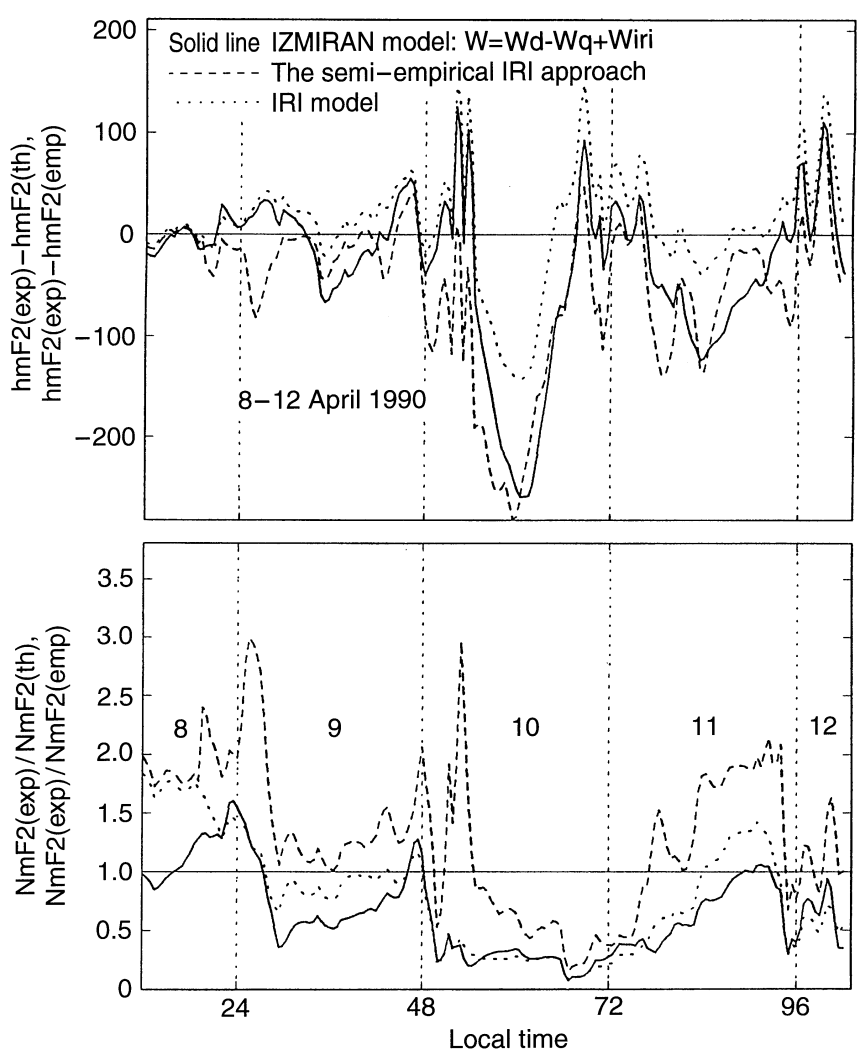

Fig. 12. Comparison of measured densities and heights with peak densities and heights given by the IZMIRAN model, the IRI-90 model, and the semiempirical IRI approach described by Kishcha (1995) for the period of 6-12 April 1990. The curves are the same as in Fig. 11

By using the algorithm (Eqs. A.21-A.23), we can forecast the values of $\mathrm{NmF} 2$ and $\mathrm{hmF} 2$ during magnetic storms. Such predictions of $\mathrm{NmF} 2$ and $\mathrm{hmF} 2$ are also possible to carry out using the semiempirical IRI approach described by Kishcha (1995) (a discussion of this approach is in Appendix A). In addition to storm effects, the semiempirical IRI approach takes into account substorm effects in $\mathrm{NmF} 2$ and hmF2.

The dotted and dashed lines in Figs. 11 and 12 show results when the modeled F2 peak densities and heights are given by IRI-90 (Bilitza, 1990) and the semiempirical IRI approach described by Kishcha (1995) (both storms and substorms inputs) were used. We can see that sometimes the theoretical results and the semiempirical IRI approach describe the experimental data well, but often they differ greatly from the measured NmF2 and hmF2. To establish how good or bad a forecast can be it is necessary to define a quantitative measure of its success. For a large number $(M)$ of forecasts of $\mathrm{NmF} 2$ and hmF2 during magnetic storms, we can compute root-mean-square errors as

$$
\begin{aligned}
& \varepsilon_{1}=\left\{\sum_{s=1}^{M}\left[\mathrm{hmF} 2_{\mathrm{s}}(\exp )-\mathrm{hmF} 2_{\mathrm{s}}(f)\right]^{2} / \mathrm{M}\right\}^{1 / 2}, \\
& \varepsilon_{2}=\left\{\sum_{s=1}^{M}\left[\mathrm{NmF} 2_{\mathrm{s}}(\exp )-\mathrm{NmF} 2_{\mathrm{s}}(f)\right]^{2} / \mathrm{M}\right\}^{1 / 2},
\end{aligned}
$$

where $h m F 2_{S}(\exp )$ and $\mathrm{NmF}_{\mathrm{S}}(\exp )$ are the measured $\mathrm{hmF} 2$ and $\mathrm{NmF} 2$ and $\mathrm{hmF}_{S}(f)$ and $\mathrm{NmF}_{S}(f)$ are forecasts of NmF2 and hmF2 given by IRI-90, the semi empirical IRI approach and the IZMIRAN model.

Table 1 gives the calculated $\varepsilon_{1}$ and $\varepsilon_{2}$ for the 18-23 March and 8-12 April storm periods. We can see that the use of the semiempirical IRI approach gives a slightly better agreement between measured and modeled NmF2 than the IZMIRAN model, and the semi empirical IRI approach gives the worst forecast of hmF2. The best agreement between the measured and modeled hmF2 is the IZMIRAN model for the March storm and the IRI-90 model for the April storm. In general, our results do not confirm very optimistic conclusions given by Kishcha (1995): "the IRI model can significantly be improved under disturbed conditions up to the factor 2 on the average with the proposed updating technique". There is no reason to assert that conditions from Eqs. A.9, A.10, A.13 (see Appendix A) that form the basis for derivation of the analytical equations used by Kishcha (1995) are valid during all storms, but during some storms Eqs. A.14, A.15 may be valid with some errors.

In modeling the March and April magnetic storms we had the measured hmF2 and we used the method developed by Richards (1991) with our modification Eqs. (A.18, A.20) to calculate an equivalent plasma drift velocity. If we use the resulting $\mathrm{NmF} 2$ instead of $\mathrm{NmF} 2(f)$ in Eq. 10 then $\varepsilon_{2}=1.8 \cdot 10^{5} \mathrm{~cm}^{-3} \varepsilon_{2}=3.0$ $10^{5} \mathrm{~cm}^{-3}$ for the 18-23 March and 8-12 April periods. These inaccuracies in the modeled $\mathrm{NmF} 2$ are less than those given by the IZMIRAN model using the algorithm Eqs. A.21-A.23) for the April storm. However, for the 18-23 March period, the root-mean-square error of $\mathrm{NmF} 2$ given by the IZMIRAN model is less if the algorithm (Eqs. A. 21-A.23) is used.

\section{Conclusions}

A comparison of the Millstone Hill ionospheric-stormtime measurements of the electron density and temperature with the model results is presented for the

\begin{tabular}{lllll}
\hline & \multicolumn{3}{l}{ 18-23 March } & \multicolumn{2}{l}{ 8-12 April } \\
& $\varepsilon_{1}(\mathrm{~km})$ & $\varepsilon_{2}\left(10^{5} \mathrm{~cm}^{-3}\right)$ & $\varepsilon_{1}(\mathrm{~km})$ & $\varepsilon_{2}\left(10^{5} \mathrm{~cm}^{-3}\right)$ \\
\hline IRI-90 & 73 & 1.7 & 55 & 3.9 \\
Kishcha (1995) & 66 & 1.3 & 89 & 3.3 \\
The IZMIRAN model & 52 & 1.5 & 80 & 3.8 \\
\hline
\end{tabular}

Table 1. Forecasting root-mean-square errors of hmF2 and NmF2 
magnetically quiet and disturbed periods on 16-23 March and 6-12 April. The CEDAR standard (Eq. 3) for the ion-neutral $\mathrm{O}^{+}-\mathrm{O}$ collision frequency for momentum transfer presented by Salah (1993), which is larger than other commonly accepted frequencies, gives the best agreement between measured and modeled $\mathrm{NmF} 2$. The recombination rate of $\mathrm{O}^{+}\left({ }^{4} \mathrm{~S}\right)$ ions was decreased by a factor of 1.5 at all altitudes during the nighttime periods 17-18 March 19-20, March 6-7, April 7-8 April and 9-10 April in order better to increase the $\mathrm{NmF} 2$ at night to match observations.

We often have not obtained the observed hmF2 and cannot use the method based on the Richards (1991) approach. In this case the IRI hmF2 can be used to calculate an equivalent plasma drift velocity for undisturbed conditions by using the modified Richards method. After that we can calculate the wind-induced plasma drift velocity for undisturbed and disturbed conditions in the usual way, without using the IRI hmF2, by solving two momentum equations for the horizontal components of thermospheric wind. Finally, we obtain the plasma drift velocity in the ion continuity equations $W=W_{d}-W_{d}-W_{q}+W_{\mathrm{IRI}}$. On 8-12 April the inaccuracy in the modeled NmF2 $\left(3.8 \cdot 10^{5} \mathrm{~cm}^{-3}\right)$ is about the same as when we use the measured hmF2 and the modified Richards (1991) method $\left(3.0 \cdot 10^{5} \mathrm{~cm}^{-3}\right)$. For the 18-23 March 1990 period, the root-mean-square errors of NmF2 given by the IZMIRAN model with and without using the measured hmF2 are $1.8 \cdot 10^{5} \mathrm{~cm}^{-3}$ and $1.5 \cdot 10^{5} \mathrm{~cm}^{-3}$, and the forecast of $\mathrm{NmF} 2$ is better if the algorithm of Eqs. A.21-A.23 is used.

Inclusion of vibrationally excited $\mathrm{N}_{2}$ brings the model and data into better agreement. For both March and April the effect of vibrationally excited $\mathrm{N}_{2}$ on $N_{e}$ and $T_{e}$ is most pronounced during the daytime, with factors of up to 4 and 3.5 reduction in the daytime peak density for March and April, respectively, due to the inclusion of vibrationally excited $\mathrm{N}_{2}$.

The derivations from the Boltzmann distribution for the first five vibrational levels of $\mathrm{N}_{2}$ were calculated. The present study suggests that the calculated distribution is highly non-Boltzmann at the vibrational levels $j>2$, and the deviations from the Boltzmann distribution are not significant at the first and second vibrational levels of $\mathrm{N}_{2}$. It was found that the Boltzmann-distribution assumption can lead to the $10-20 \%$ increase in the calculated $\mathrm{NmF} 2$ in comparison with $\mathrm{NmF} 2$ calculated using the non-Boltzmann vibrational distribution of $\mathrm{N}_{2}$. The calculations also showed that the vibrational temperature during the quite periods is less then during, the magnetic-storm periods. During the daytime the high vibrational temperature stems from the enhanced thermal excitation of $\mathrm{N}_{2}$ as a result of high thermal electron temperatures at F2-region altitudes, while the decrease in the vibrational temperature compared to the regular temperature is due to the decreases in the electron density and the neutral temperature.

During the March storm at solar maximum the model results obtained by using the EUVAC flux model agree a little better with the observations in comparison with those using the EUV94 flux model. If we use
EUVAC model, then in general the Boltzmann vibrational $\mathrm{N}_{2}$-distribution assumption gives better agreement between measured and modeled NmF2 than the non-Boltzmann vibrational distribution of $\mathrm{N}_{2}$. To improve this agreement in the ionospheric model with EUV94X fluxes it is necessary to use a non-Boltzmann vibrational distribution of $\mathrm{N}_{2}$ which is more correct. For the April storm period of moderate solar activity the EUV94X model results agree better with the observations in comparison to using the EUVAC model. The resulting effect on the $\mathrm{NmF} 2$ is an approximate $10-40 \%$ increase in NmF2 using the EUVAC model. The resulting effect on the NmF2 is an approximate 10$40 \%$ increase in NmF2 using the EUV94X model compared to the EUVAC model, and this effect is most pronounced during the daytime.

The preceding results indicate that the extremely low NmF2 and hmF2 between 9.30 and 14.30 LT on 10 April cannot be explained by the effects of the measured electric fields and neutral winds on the ionosphere in the frame of our one-dimensional time-dependent theoretical model. We believe that this plasma depletion in the flux tube with extremely low NmF2 and hmF2 is created in the midlatitude ionospheric trough and this flux tube is transferred by horizontal plasma convection. In general, the use of the measured $\mathrm{E}_{\perp}$ and meridional neutral winds as input model parameters does not improve the agreement between the data and the theoretical results giving higher NmF2. This means that there are other sources of uncertainty in the model, such as uncertainties of model input data and physical processes and errors in the measured $\mathrm{E}_{\perp}$ and meridional neutral winds.

The NmF2 and hmF2 calculated by using the IZMIRAN model with algorithm of Eqs. A.21-A.23, or by using the semiempirical IRI approach given by Kishcha (1995), sometimes describe the experimental data well, but often differ greatly from the measured $\mathrm{NmF} 2$ and hmF2. In general, the use of the semiempirical IRI approach gives a slightly better agreement between measured and modeled NmF2 than the IZMIRAN model, and the semiempirical IRI approach gives the worst forecast of $\mathrm{hmF} 2$. The agreement between the measured and modeled hmF2 is best when the IZMIRAN model was used during the March and or April storms when the IRI-90 model was used to calculate NmF2.

\section{Appendix A}

The IZMIRAN model gives the numerical solution of continuity, energy, and momentum equations, but from this very complicated model it is difficult to find reasons for agreement or disagreement between measured $\mathrm{NmF} 2$ and $\mathrm{hmF} 2$ and modeled $\mathrm{NmF} 2$ and $\mathrm{hmF} 2$. For the physical interpretation of our modeled results (but not for calculations of $\mathrm{NmF} 2$ and hmF2) we use Eqs. 4 and 5 for nighttime and equations for daytime $\mathrm{NmF} 2$ and $\mathrm{hmF} 2$ obtained here.

In order to find the analytical solution of the steady-state continuity equation for $\mathrm{O}^{+}\left({ }^{4} \mathrm{~S}\right)$ ions $\left[\mathrm{O}^{+}\left({ }^{2} \mathrm{D}\right)\right.$ and $\mathrm{O}^{+}\left({ }^{2} \mathrm{P}\right)$ ions are not considered] during quiet days, Badin and Deminov (1982) and Badin (1989) assumed that the optical depth of the atmosphere goes 
to zero, the drift velocity of the plasma in the vertical direction $W \approx$ const, $T_{i} \approx$ const, $T_{n} \approx$ const, $T_{e} \approx$ const and the effects of $\mathrm{N}_{2}^{*}$ on the electron density tend to zero. Pavlov (1987) took into consideration the effects of $\mathrm{N}_{2}^{*}$ on the $\mathrm{O}^{+}\left({ }^{4} \mathrm{~S}\right)$ ion density and simplified the $\mathrm{NmF} 2$ and $\mathrm{hmF} 2$ given by Badin and Deminov (1982) by assuming that $[\mathrm{O}]^{2} /\left[\mathrm{N}_{2}\right] \approx$ const and $T_{y} \approx$ const. If we take into account the $\mathrm{O}^{+}\left({ }^{2} \mathrm{D}\right)$ and $\mathrm{O}^{+}\left({ }^{2} \mathrm{P}\right)$ ions and a production of the $\mathrm{O}^{+}\left({ }^{4} \mathrm{~S}\right), \mathrm{O}^{+}\left({ }^{2} \mathrm{D}\right)$, and $\mathrm{O}^{+}\left({ }^{2} \mathrm{P}\right)$ ions due to photoelectrons then

$\mathrm{NmF} 2\left(\mathrm{~cm}^{-3}\right) \approx I \mathrm{v}_{\text {in }}^{1 / 3}[O]\left(T_{n} / L^{2}\right)^{1 / 3} \exp \left(V f_{1}\right)$,

$\mathrm{hmF} 2(\mathrm{~km}) \approx h_{0}+1.92 \cdot 10^{-2} T_{n}\left(\ln f_{0}+f_{2}+f_{3} V\right)$,

where $h_{0}=300 \mathrm{~km}, \quad f_{1}=0.092+0.424 y, \quad f_{2}=6.273 y-6.717$, $f_{3}=1.055 y+0.481, \quad y=T_{n} /\left(T_{i}+T_{e}\right), \quad y \geq 0.2, \quad V=8.7 .10^{-4}$ $W v_{\text {in }}^{2 / 3}\left(T_{n} L\right)^{-1 / 3}, \quad f_{0}=2.15 T_{n} L \mathrm{v}_{\text {in }}, \mathrm{v}_{\text {in }}$ is momentum transfer collision frequency of $\mathrm{O}^{+}-\mathrm{O}$ ), $L$ is determined by Eq. 5 , the units of [O] are $\mathrm{cm}^{-3}$ and the units of $W$ are $\mathrm{cm} \mathrm{s}^{-1}$; and Eqs. A.1-A.2 are valid if $\left|V_{f_{1}}\right|<1$.

The ionization frequency, $I$, gives a linear relationship between $\mathrm{NmF} 2$ and the solar EUV fluxes as follows

$$
\begin{aligned}
I= & I_{1}+I_{\mathrm{le}}+\left[\mathrm{O}^{+}\left({ }^{2} \mathrm{D}\right)\right] K_{1}+\left[\mathrm{O}^{+}\left({ }^{2} \mathrm{P}\right)\right] \\
& \left\{K_{2}[\mathrm{O}]+K_{3}\left[\mathrm{~N}_{2}\right]+K_{4}\right\}[\mathrm{O}],
\end{aligned}
$$

where

$$
\begin{aligned}
{\left[\mathrm{O}^{+}\left({ }^{2} \mathrm{P}\right)\right]=} & \left(I_{2}+I_{2 \mathrm{e}}\right)[\mathrm{O}] /\left\{K_{4}+K_{5}+K_{2}[\mathrm{O}]+K_{3}\left[\mathrm{~N}_{2}\right]\right), \\
{\left[\mathrm{O}^{+}\left({ }^{2} \mathrm{D}\right)\right]=} & \left\{\left(I_{3}+I_{3 \mathrm{e}}\right)[\mathrm{O}]+K_{5}\left[\mathrm{O}^{+}\left({ }^{2} \mathrm{P}\right)\right]\right\} / \\
& \left\{K_{6}\left[\mathrm{~N}_{2}\right]+K_{7}\left[\mathrm{O}_{2}\right]+K_{1}[\mathrm{O}]\right\},
\end{aligned}
$$

photoionization production frequencies of the $\mathrm{O}^{+}\left({ }^{4} \mathrm{~S}\right), \mathrm{O}^{+}\left({ }^{2} \mathrm{D}\right)$, and $\mathrm{O}^{+}\left({ }^{2} \mathrm{P}\right)$ ions

$$
\begin{aligned}
I_{1} & =\sum_{\lambda} F(\lambda) \sigma_{1}(\lambda), \quad I_{2}=(\lambda) \sum_{\lambda} F \sigma_{2}(\lambda), \\
I_{3} & =\sum_{\lambda} F(\lambda) \sigma_{3}(\lambda),
\end{aligned}
$$

production frequencies of the $\mathrm{O}^{+}\left({ }^{4} \mathrm{~S}\right), \mathrm{O}^{+}\left({ }^{2} \mathrm{D}\right)$, and $\mathrm{O}^{+}\left({ }^{2} \mathrm{P}\right)$ ions due to photoelectrons are calculated by using the approximation approach given by Krinberg (1978) with the correction factor given by Pavlov (1994)

$I_{\mathrm{le}}=\sum_{\lambda=0}^{\mathrm{A}} F(\lambda) \sigma_{1}(\lambda) G(\lambda), \quad I_{2 \mathrm{e}}=\sum_{\lambda=0}^{\mathrm{A}} F(\lambda) \sigma_{2}(\lambda) G(\lambda)$,

$I_{3 \mathrm{e}}=\sum_{\lambda=0}^{\mathrm{A}} F(\lambda) \sigma_{3}(\lambda) G(\lambda)$

$F(\lambda)$ is the intensity of the solar EUV flux radiation at a specified wavelength $\lambda$. The photoionization crossections $\sigma_{1}, \sigma_{2}$, and $\sigma_{3}$ for atomic oxygen with the formation of $\mathrm{O}^{+}\left({ }^{4} \mathrm{~S}\right), \mathrm{O}^{+}\left({ }^{2} \mathrm{D}\right)$, and $\mathrm{O}^{+}\left({ }^{2} \mathrm{P}\right)$ ions have been presented by Richards et al. (1994a), where the correction factor $G(\lambda)=0.8(A / \lambda-1), A=56.3 \mathrm{~nm}$, and $K_{1}-K_{7}$ are the rate coefficients of the chemical reactions displayed in
Table 2. In Eqs. A.1-A.3 the values of $[\mathrm{O}],\left[\mathrm{O}_{2}\right],\left[\mathrm{N}_{2}\right], T_{n}, T_{e}, T_{i}, T_{v}$, and $W$ are taken at $h_{0}$ altitude. We take into account the input of $\mathrm{O}^{+}\left({ }^{2} \mathrm{D}\right)$ and $\mathrm{O}^{+}\left({ }^{2} \mathrm{P}\right)$ ions without including the reaction of $\mathrm{O}^{+}\left({ }^{2} \mathrm{D}\right)$ and $\mathrm{O}^{+}\left({ }^{2} \mathrm{P}\right)$ ions with electrons, and assume that $I \approx$ const.

Let us compare the disturbed $\mathrm{NmF} 2(d), \operatorname{hmF} 2(d)$ with the undisturbed $\mathrm{NmF} 2(q), \operatorname{hmF} 2(q)$. If we consider that

$T_{\mathrm{i}}=T_{\mathrm{n}}, \mathrm{v}_{\text {in }}=\operatorname{const} \sqrt{T}_{\mathrm{n}}[\mathrm{O}]$,

and the values of $C_{f}, I, V f_{1}, f_{2}$, and $f_{3} V$ are about the same for both the undisturbed period and magnetic storm:

$I(\mathrm{q}) \exp \left[\mathrm{V}(\mathrm{q}) \mathrm{f}_{1}(\mathrm{q})\right] \approx I(d) \exp \left[\mathrm{V}(\mathrm{d}) \mathrm{f}_{1}(\mathrm{~d})\right]$,

$\left|T_{n}(d) \ln f_{0}(d)-T_{n}(q) \ln f_{0}(q)\right|>>\mid f_{2}(d)+$

$f_{3}(d) V(d)-f_{2}(q)+f_{3}(q) V(q) \mid$,

then

$\mathrm{NmF} 2(d) / \operatorname{NmF} 2(q)=\mathrm{a}(d) / \mathrm{a}(q)$,

$\operatorname{hmF} 2(d)-\operatorname{hmF} 2(q)=1.92 .10^{-2}$

$$
\left[\mathrm{T}_{\mathrm{n}}(\mathrm{d}) \ln \mathrm{f}_{0}(\mathrm{~d})-\mathrm{T}_{\mathrm{n}}(\mathrm{q}) \ln \mathrm{f}_{0}(\mathrm{q})\right],
$$

where $a=\left\{[\mathrm{O}]^{2} / L\right\}^{2 / 3} \sqrt{T}_{n}$.

If also

$L \approx$ const $\left[\mathrm{N}_{2}\right]\left(T_{n}\right)^{2}, T_{n}(d) \approx T_{n}(q)=T$,

then

foF $2(d) /$ foF $2(q)=A(d) / A(q)$,

$\operatorname{hmF} 2(d)-\operatorname{hmF} 2(q)=1.92 \cdot 10^{-2} T \ln [\mathrm{B}(\mathrm{d}) / \mathrm{B}(\mathrm{q})]$,

where foF2 is the critical frequency of the F2 layer peak, $\left.A=\left(T_{n}\right)^{-5 / 12}\left\{[\mathrm{O}]^{2} / \mathrm{N}_{2}\right]\right\}^{1 / 3}, B=[\mathrm{O}]\left[\mathrm{N}_{2}\right]\left(T_{n}\right)^{3.5}$

The Eqs. A.14-A.15 with the same value of the $B$ coefficient but another value of $A=\left\{\left(T_{n}\right)^{-2}[\mathrm{O}] /\left[\mathrm{N}_{2}\right]^{16 / 28}\right\}^{0.65}$ were used by Kishcha (1995) to describe the foF2 and hmF2 variations during several magnetic storms. Substorm effects were taken into account by Kishcha (1995) using a simple analytical description.

There is absolutely no reason to assert that conditions of Eqs. A.9-A.11 are valid during all storms, but during some storms Eqs. (A.14)-(A.15) may be valid with some small errors. The results presented in this paper show that the algorithm used by Kishcha (1995) gives satisfactory agreement between the measured $\mathrm{NmF} 2(d) / \mathrm{NmF} 2(q)$ and $\operatorname{hmF} 2(d)-\operatorname{hmF} 2(q)$ and the calculated $\mathrm{NmF} 2(d) / \mathrm{NmF} 2(q)$ and $\mathrm{hmF} 2(d)-\mathrm{hmF} 2(q)$ during the March and April storms, though often results differ greatly from the measured $\mathrm{NmF} 2$ and $\mathrm{hmF} 2$.

Equation A.2 can also be used in the method developed by Richards (1991) to calculate an equivalent neutral wind from the the hmF2 measurements. In this method the equivalent neutral wind at the next time-step

$U(t+\Delta t)=\left(h_{\exp }(t+\Delta t)-h^{\prime}(t)\right) / \alpha(t)+U^{\prime}(t)$,

\begin{tabular}{lll}
\hline Reaction & Rate coefficient & Reference \\
\hline $\mathrm{O}^{+}\left({ }^{2} \mathrm{D}\right)+\mathrm{O} \rightarrow \mathrm{O}^{+}\left({ }^{4} \mathrm{~S}\right)+\mathrm{O}$, & $K_{1}=10^{-10} \mathrm{~cm}^{3} \mathrm{~s}^{-1}$ & Fox and Dalgarno (1985) \\
$\mathrm{O}^{+}\left({ }^{2} \mathrm{P}\right)+\mathrm{O} \rightarrow \mathrm{O}^{+}\left({ }^{4} \mathrm{~S}\right)+\mathrm{O}$, & $K_{2}=4.10^{-10} \mathrm{~cm}^{3} \mathrm{~s}^{-1}$ & Chang et al. $(1993)$ \\
$\mathrm{O}^{+}\left({ }^{2} \mathrm{P}\right)+\mathrm{N}_{2} \rightarrow \mathrm{O}^{+}\left({ }^{4} \mathrm{~S}\right)+\mathrm{N}_{2}$, & $K_{1}=3.4 \cdot 10^{-10} \mathrm{~cm}^{3} \mathrm{~s}^{-1}$ & Chang et al. $(1993)$ \\
$\mathrm{O}^{+}\left({ }^{2} \mathrm{P}\right) \rightarrow \mathrm{O}^{+}\left({ }^{4} \mathrm{~S}\right)+\mathrm{h} v$, & $K_{4}=0.047 \mathrm{~s}^{-1}$ & Seaton and Osterbrock (1957) \\
$\mathrm{O}^{+}\left({ }^{2} \mathrm{P}\right) \rightarrow \mathrm{O}^{+}\left({ }^{4} \mathrm{D}\right)+\mathrm{h} v$, & $K_{5}=0.172 \mathrm{~s}^{-1}$ & Seaton and Osterbrock(1957) \\
$\mathrm{O}^{+}\left({ }^{2} \mathrm{D}\right)+\mathrm{N}_{2} \rightarrow \mathrm{N}_{2}^{+}+\mathrm{O}$, & $K_{6}=8 \cdot 10^{-10} \mathrm{~cm}^{3} \mathrm{~s}^{-1}$ & Johnsen and Biondi (1980) \\
$\mathrm{O}^{+}\left({ }^{2} \mathrm{D}\right)+\mathrm{O}_{2} \rightarrow \mathrm{O}^{+}+\mathrm{O}$, & $K_{7}=7 \cdot 10^{-10} \mathrm{~cm}^{3} \mathrm{~s}^{-1}$ & Johnsen and Biondi (1980) \\
$\mathrm{O}^{+}\left({ }^{2} \mathrm{P}\right)+\mathrm{e} \rightarrow \mathrm{O}^{+}\left({ }^{4} \mathrm{~S}\right)+\mathrm{e}$, & $K_{8}=4.7 \cdot 10^{-8}\left(300 / T_{e}\right)^{0.5} \mathrm{~cm}^{3} \mathrm{~s}^{-1}$ & Torr and Torr (1982) \\
$\mathrm{O}^{+}\left({ }^{2} \mathrm{D}\right)+\mathrm{e} \rightarrow \mathrm{O}^{+}\left({ }^{4} \mathrm{~S}\right)+\mathrm{e}$, & $K_{9}=7.8 \cdot 10^{-8}\left(300 / T_{e}\right)^{0.5} \mathrm{~cm}^{3} \mathrm{~s}^{-1}$ & Torr and Torr (1982) \\
\hline
\end{tabular}

Table 2. Chemistry of metastable ions 
where $h_{\exp }(t+\Delta t)$ is the measured F2-layer peak altitude at time $t+\Delta t, h^{\prime}(t)$ and $U^{\prime}(t)$ are the calculated heights of the F2 layer and the equivalent neutral wind at time $t$.

The value of $\alpha(t)$ is determined by modeling the diurnal variation of the $\mathrm{F}$ region as

$\left.\alpha(t)=\left(h_{1}(t)-h_{2}(t)\right) / U_{1}(t)-U_{2}(t)\right)$.

Where $h_{1}(t)$ is the calculated height of the F2-layer peak for $U=U_{1}(t)$ at time $t$ and $h_{2}(t)$ is the calculated height of the F2-layer peak for $U=U_{2}(t)$ at time $t$, subscripts 1 and 2 refer to two separate model calculations at time $t$ with the input parameters $U=U_{1}(t)$ and $U=U_{2}(t)$.

$W(t+\Delta t)=\left(h_{\exp }(t+\Delta t)-h^{\prime}(t)\right) / \beta(t)+W^{\prime}(t)$,

$\beta(t)=\left(h_{1}(t)-h_{2}(t)\right) /\left(W_{1}(t)-W_{2}(t)\right)$,

where $h^{\prime}(t)$ and $W^{\prime}(t)$ are the calculated heights of the F2 layer and the equivalent drift velocity of the plasma at time $t, h_{1}(t)$ and $h_{2}(t)$ are the calculated heights of the F2-layer peak for $W=W_{1}(t)$ and $W=W_{2}(t)$. In this case, from Eq. A.2 it follows that

$\beta(t)=\frac{\partial}{\partial} \bar{W} \mathrm{hmF} 2=1.67 \cdot 10^{-5} f_{3}\left(T_{n} v_{i n}\right)^{2 / 3} L^{-1 / 3}$,

where the values of $f_{3}, T_{n}, v_{\text {in }}$, and $L$ are given at $300-\mathrm{km}$ altitude (the dependence of $\beta$ on altitude is small at the F-region altitudes because of $\left.\beta(t) \sim\left\{[\mathrm{O}]^{2} / L\right\}^{1 / 3}\right)$.

Note that approximation Eq. A.2 is valid only during a quiet daytime period. But from our calculations we found that the use of Eqs. A.18, A.20 gives hmF2 to sufficient accuracy during daytime and nighttime quiet and disturbed periods. The reason for this conclusion is that the values of $\alpha(t)$ and $\beta(t)$ do not have to be known precisely (Richards, 1991)

We often do not have the observed hmF2 and thus cannot use the method developed by Richards (1991) or our modification Eqs. A.18, A.20 to calculate an equivalent plasma drift velocity. To overcome this problem, we can try to use $\mathrm{hmF} 2_{\text {IRI }}$ given by the IRI-90 model (Bilitza, 1990) to calculate an equivalent plasma drift velocity, $W_{\text {IRI }}$, for some hypothetical undisturbed conditions with the same solar and time conditions as during the studied geomagnetic storm:

$W_{I R I}(t+\Delta t)=\left(\mathrm{hmF}_{\text {IRI }}(t+\Delta t)-\operatorname{hmF} 2(t)\right) / \beta(t)+W_{I R I}(t)$,

where $\operatorname{hmF} 2(t)$ and $W_{\mathrm{IRI}}(t)$ are the calculated heights of the F2 layer and the equivalent drift velocity of the plasma at time $t$, and the value of $\beta(t)$ is calculated from Eq. A.20.

After that we calculate the wind-induced plasma drift velocities

$W_{\mathrm{q}}=U_{\Theta}(q) \cos I, \quad W_{d}=U_{\Theta}(d) \cos I$,

where $U_{\Theta}$ is the component of the thermospheric wind for quiet $(q)$ or disturbed $(d)$ conditions in spherical polar coordinates $(r, \Theta, \Phi)$, $r$ denotes radical distance from the Earth's center $\Theta$ is the geomagnetic colatitude, $\phi$ is the geomagnetic longitude, $I$ is the magnetic field dip angle and $U_{\Theta}(q)$ and $U_{\theta}(d)$ are obtained by solving two momentum equations for the horizontal components of thermospheric wind (Pavlov, 1994).

Finally, the plasma drift velocity in the ion continuity equations is given by Pavlov (1995) as

$W=W_{d}-W_{q}+W_{I R I}$.

Acknowledgments. Millstone Hill radar operations and analysis are supported by National Science Foundation Cooperative Agreement ATM-94-08609 to the Massachusetts Institute of Technology. A portion of this work, while A. Pavlov was in residence at the Haystack Observatory, was supported by NSF grant ATM-93-01895 to MIT. In 1996 support for A.V. Pavlov was provided by grant 96-05-64031 from the Russian Foundation of
Fundamental Researches. We would like to thank Dr. B. Emery and an anonymous referee for critical reading of the manuscript as reviewers and for constructive comments which have helped improve the paper.

Topical Editor D Alcaydé thanks B. Eméry and G. Khazanor for their help in evaluating this paper.

\section{References}

Abdou, W. A., D. G. Torr, P. G. Richards, M. R. Torr, and E. L. Breig, Results of a comprehensive study of the photochemistry of $\mathrm{N}_{2}^{+}$in the ionosphere, J. Geophys. Res., 89, $9069-9079$, 1984.

Albritton, D. L., I. Dotan W. Lindinger, M. Mc Farland, J. Tellinghuisen, and F. C. Fehsenfeld, Effects of ion speed distribution in flow-drift tube studies of ion-neutral reactions, J. Chem. Phys., 66, 410-421, 1977.

Badin, V. I., Analytical dependencies of the electron density and peak height of the daytime F2 layer on plasma drift velocity and other parameters of the atmosphere, (in Russian) Geomagn. Aeron., 29, 795-798, 1989.

Badin, V. I., and M. G. Deminov, Plasma drift effect on the F2region ionospheric structure (in Russian) in Ionospheric forecast, Eds. R. A. Zevakina and N. P. Sergienko, Nauka, Moscow, pp 79-81, 1982.

Banks, P. M., Collision frequencies and energy transfer electrons, Planet. Space Sci., 14, 1085-1090, 1966.

Biltza D., Progress report on IRI status, Adv. Space Res., 10, (11),3-(11),5, 1990.

Buonsanto, M. J., Seasonal variations of day-time ionisation flows inferred from a comparison of calculated and observed $\mathrm{NmF}$, J. Atmos, Terr. Phys., 48, 365-373, 1986.

Buonsanto, M. J., J. C. Foster, and D. P. Sipler, Observations from Millstone Hill during the geomagnetic disturbances of March and April 1990, J. Geophys. Res., 97, 1225-1243, 1992a.

Buonsanto, M. J., Y. K. Tung, and D. P. Sipler, Neutral atomic oxygen density from nighttime radar and optical wind measurements at Millstone Hill, J. Geophys. Res., 97, 86738679, $1992 b$.

Buonsanto, P. G. Richards, W. K. Tobiska, S. C. Solomon, Y. -K. Tung, and J.A.Fennelly, Ionosperic electron densities calculated using different EUV flux models and cross-sections: comparison with radar data, J. Geophys. Res., 100 14569-114580, 1995.

Burnside, R. G., C. A. Tepley, and V. B. Wickwar, The $\mathrm{O}^{+}-\mathrm{O}$ collision cross-section: can it be inferred from aeronomical measurements? Ann. Geophysicae, 5, 343-350, 1987.

Chang, T., P. G. Richards, and D. G. Torr, Reevaluation of the $\mathrm{O}^{+}\left({ }^{\mathrm{a}} \mathrm{P}\right)$ reaction:rate coefficients derived from Atmosphere Explorer C observation, J. Geophys. Res., 98, 15589-15597, 1993.

Chen, A., R. Johnsen, and M. A. Biondi, Measurements of the $\mathrm{O}^{+}+$ $\mathrm{N}_{2}$ and $\mathrm{O}^{+}+\mathrm{O}_{2}$ reactions rates from 300 to $900 \mathrm{~K}$, Chem. Phys., 69, 2688-2691, 1978.

Davis, C. J., A. D. Farmer, and A. Aruliah, An optimised method for calculating the $\mathrm{O}^{+}-\mathrm{O}$ collision parameter from aeronomical measurements, Ann. Geophysicae, 13, 541-550, 1995.

Ferguson, E. E., comment on "The effect on the thermospheric chemistry of a resonant charge-exchange reaction involving vibrationally exicited $\mathrm{N}_{2}^{+}$ions with atomic oxygen" by W.A. Abdou et al., J. Geophys. Res., 89, 399-400, 1984.

Foster, J. C., M. J. Buonsanto, M. Mendillo, D. Nottingham, F. C. Rich, and W. Denig, Coordinated stable auroral red arc observations: relationship to plasma convection, J. Geophys. Res., 99, 11429-11439, 1994.

Fox, J. L. and A. Dalgarno, The vibrational distribution of $\mathrm{N}_{2}^{+}$in the terrestrial ionosphere, J. Geophys. Res., 90, 7557-7567, 1985

Hedin, A. E., MSIS-86 thermospheric model, J.Geophys. Res., 92 , 4649-4662, 1987. 
Johnsen, R., and M. A. Biondi, Laboratory measurements of the $\mathrm{O}^{+}\left({ }^{2} \mathrm{D}\right)+\mathrm{N}_{2}$ and $\mathrm{O}^{+}\left({ }^{2} \mathrm{D}\right)+\mathrm{O}_{2}$ reaction rate coefficients and their ionospheric implications, Geophys. Res. Lett., 7, 401-403, 1980.

Kashirin., A. I., Photoionization in the night-time ionosphere (in Russian) Geomagn. Aeron., 26, 563-568, 1986.

Kishcha, P. V., Indices and updating procedures for modeling of ionospheric disturbances, Adv. Space Res., 16, 55-64, 1995.

Krinberg, I. A., Electron kinetics in the earth's ionosphere and plasmasphere (in Russian) Nauka, Moscow, 1978.

Krinberg, I. A. and A. V. Tashchilin, Refilling of geomagnetic force tubes with a thermal plasma after magnetic disturbance, Ann. Geophysicae, 38, 25-32, 1982.

Krinberg, I. A., and A. V. Tashchilin, Ionosphere and plasmasphere, (in Russian) Nauka, Moscow, 1984.

Miller, K. L., D. G. Torr, and P. G. Richards, Meridional winds in the thermosphere derived from measurements of F2-layer height, J. Geophys. Res., 91, 4531-4538, 1986.

Moffett, R. J., R. Sellek, and G. J. Balley, The influence of $\mathrm{O}^{+}-\mathrm{O}$ collision frequency on ionospheric F-region behaviour, $J$. Atmos. Terr. Phy., 52, 125-132, 1990.

Newton, G. P., J. C. G. Walker, and P. H. E. Meijer, Vibrationally excited nitrogen in stable auroral red arcs and its effect on ionospheric recombination, J. Geophys. Res., 79, 3807-3818, 1974.

Oppenheimer, M., E. R. Constantinides, K. Kirby - Docken, G. A. Victor, and A. Dalgarno, Ion photochemistry of the thermosphere from Atmosphere Explorer C measurements, J. Geophys. Res., 82, 5485-5492, 1977.

Pavlov, A. V., Possible accuracy of theoretical forecasts of the major ionospheric parameters, in Forecast of disturbances in the ionosphere and magnetosphere and solar activity (in Russian), Eds. R. A. Zevakina and V. N. Obridko, Nauka, Moscow, pp 177-192, 1987.

Pavlov, A. V., The role of vibrationally excited nitrogen in the ionosphere, Pure Appl. Geophys., 127, 529-544, 1988.

Pavlov., A. V., About the role of vibrationally excited nitrogen in the sabauroral red arc region (in Russian), Geomagn. Aeron., 29, 948-953, 1989.

Pavlov, A. V., The role of vibrationally excited nitrogen in the formation of the mid-latitude ionisation trough, Ann. Geophysicae, 11, 479-484, 1993.

Pavlov, A. V., The role vibrationally excited nitrogen in the formation of the mid-latitude ionospheric storms, Ann. Geophysicae, 12, 554-564, 1994.

Pavlov, A. V., Mechanisms of the electron density depletion in the SAR arc region, Ann. Geophysicae, 14, 211-221, 1996.

Pavlov, A. V., and A. A. Namgaladze, Vibrationally excited nitrogen in the upper atmosphere. Review paper (in Russian) Geomagn. Aeron., 28, 705-721, 1988.

Pesnell, W. D., Momentum transfer collision frequency of $\mathrm{O}^{+}{ }_{-} \mathrm{O}$, Geophys. Res. Lett., 20, 1343-1346, 1993.

Raitt, W. J, Schunk R. W., and P. M. Banks, Ionospheric composition in SAR-arcs, Planet. Space Sci., 24, 105-114, 1976.

Reddy, C. A., W. R. Hoegy, W. D. Pesnell, H. G. Mayr and C. O. Hines, Accuracy of $\mathrm{O}^{+}-\mathrm{O}$ collision cross-section deduced from ionosphere-thermosphere observations, Geophys. Res. Lett., 21, 2429-2432, 1994.

Richards, P. G., An improved algorithm for determining neutral winds from the height of the F2 peak electron density, J. Geophys. Res., 96, 17839-17846, 1991.

Richards, P. G., and P. G. Torr, A factor of 2 reduction in theoretical F2 peak electron density due to enhanced vibrational excitation of $\mathrm{N}_{2}$ in summer at solar maximum, J. Geophys. Res., 91, 11331-1336, 1986.

Richards, P. G., D. G. Torr, and W. A. Abdou, Effects of vibrational enhancement of $\mathrm{N}_{2}$ on the cooling rate of ionospheric thermal electrons, J. Geophys. Res., 91, 304-310, 1986.

Richards, P. G., J. A. Fennelly, and D. G. Torr, EUVAC : A solar EUV flux model for aeronomical calculations, J. Geophys. Res., 99, 8981-8992, 1994a.

Richards, P. G., D. G. Torr, M. J. Buonsanto and D. P. Sipler, Ionospheric effects of the March 1990 magnetic storm: comparison of theory and measurements, J. Geophys. Res., 99, 23359-23365, 1994b.

Rodger, A. S., Moffett R. J., and S. Quegan, The role of ion drift in the formation of ionization troughs in the mid- and highlatitude ionosphere - a review, J. Atmos. Terr. Phys., 54, 1-30, 1992.

Salah, J. E., Interim standard for the ion-neutral atomic oxygen collision frequency, Geophys. Res. Lett., 20, 1543-1546, 1993.

Schmeltekopf, A. L., E. E. Ferguson, and F. C. Fehsenfeld, Afterglow studies of the reactions $\mathrm{He}^{+}, \mathrm{He}\left(2^{3} \mathrm{~S}\right)$, and $\mathrm{O}^{+}$with vibrationally excited $\mathrm{N}_{2}$, J. Chem. Phys., 48, 2966-2973, 1968.

Schunk, R. W., W. J. Raitt and P. M. Banks, Effect of electric fields on the daytime high-latitude E and F region, J. Geophys. Res., 80, 3121-3130, 1975.

Seaton, M. J., and D. W. Osterbrock, Relative OII intensities in gaseous nebulae, Astrophys. J., 125, 66-83, 1957.

Sipler, D. P, M. E. Hagan, M. E. Zipf and M. A. Biondi, Combined optical and radar wind measurements in the $F$ region over Millstoun Hill, J. Geophys. Res., 96, 21255-21262, 1991.

St.-Maurice, J. -P., and D. G. Torr, Nonthermal rate coefficients in the ionosphere: The reaction of $\mathrm{O}+$ with $\mathrm{N}_{2}, \mathrm{O}_{2}$ and $\mathrm{NO}$, J. Geophys. Res., 83, 969-977, 1978.

Tobiska, W. K., The empirical solar EUV irradiance model EUV94

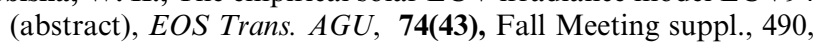
1993.

Tobiska, W. K., Modeled soft X-ray solar irrradiance, Sol. Phys., 152, 207-215, 1994.

Torr, M. R., and D. G. Torr, The role of metastable species in the thermosphere, Rev. Geophys. Space Phys., 20, 91-144, 1982.

Torr, M., R. D. G. Torr, P. G. Richards, and S. P. Yung, Mid-and low-latitude model of thermospheric emissions. $1 . \mathrm{O}^{+}\left({ }^{2} \mathrm{P}\right) 7320$ A and $\mathrm{N}_{2}\left({ }^{2} \mathrm{P}\right) 3371$ A, J. Geophys. Res., 95, 21147-21168, 1990.

Van Zandt, T. E., and T. F. O'Malley, Rate coefficient for the reaction of $\mathrm{O}^{+}$with vibrationally excited $\mathrm{N}_{2}$, J. Geophys.Res., 78, 6818-6820, 1973.

Viehland, L. A., and E. A. Mason, Statistical - mechanical theory of gaseous ion-molecule reaction in an electrostatic field, J. Chem. Phys., 66, 422-434, 1977. 